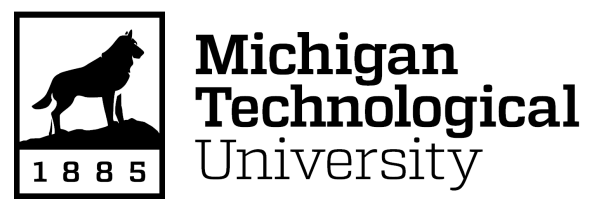

Michigan Technological University Digital Commons @ Michigan Tech

Dissertations, Master's Theses and Master's Reports

2017

\title{
HEAT TRANSFER ANALYSIS IN A PADDLE REACTOR FOR BIOMASS FAST PYROLYIS
}

Ankith Ullal

Michigan Technological University, ullal@mtu.edu

Copyright 2017 Ankith Ullal

Recommended Citation

Ullal, Ankith, "HEAT TRANSFER ANALYSIS IN A PADDLE REACTOR FOR BIOMASS FAST PYROLYIS", Open Access Master's Thesis, Michigan Technological University, 2017.

https://doi.org/10.37099/mtu.dc.etdr/313

Follow this and additional works at: https://digitalcommons.mtu.edu/etdr

Part of the Energy Systems Commons, Heat Transfer, Combustion Commons, and the Thermodynamics Commons 
HEAT TRANSFER ANALYSIS IN A PADDLE REACTOR FOR BIOMASS FAST PYROLYIS

\author{
By
}

Ankith Ullal

\title{
A THESIS
}

Submitted in partial fulfillment of the requirements for the degree of MASTER OF SCIENCE

In Mechanical Engineering

MICHIGAN TECHNOLOGICAL UNIVERSITY

2017

(C) 2017 Ankith Ullal 
This thesis has been approved in partial fulfillment of the requirements for the Degree of MASTER OF SCIENCE in Mechanical Engineering.

Department of Mechanical Engineering - Engineering Mechanics

Thesis Co-Advisor: $\quad$ Dr. Ezra Bar-Ziv
Thesis Co-Advisor: $\quad$ Dr. Jordan Klinger

Committee Member: $\quad$ Dr. David Shonnard

Committee Member: Dr. Jeffrey D. Naber

Committee Member: $\quad$ Dr. Tyler L. Westover

Department Chair: $\quad$ Dr. William Predebon 


\section{Table of contents}

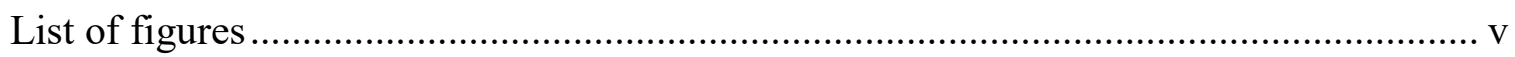

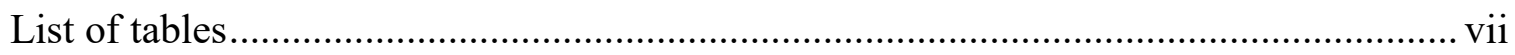

Preface

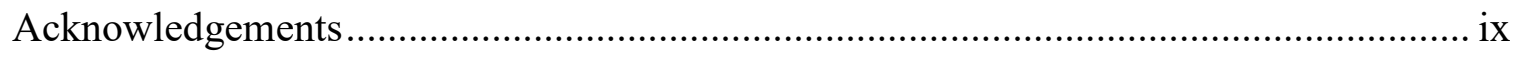

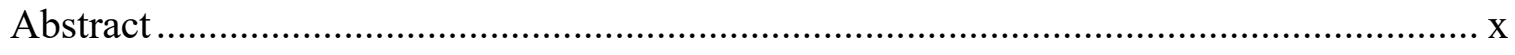

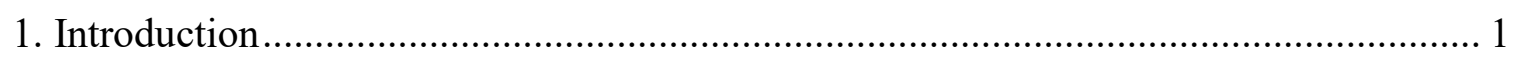

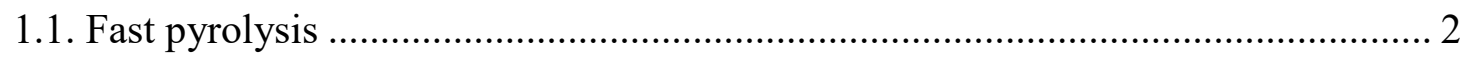

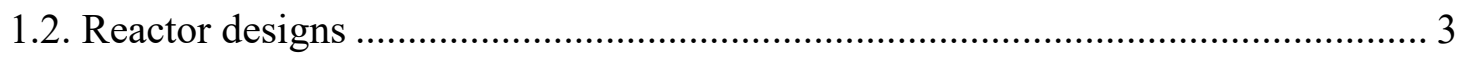

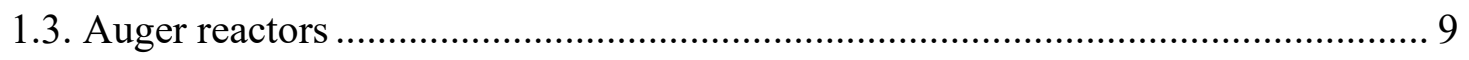

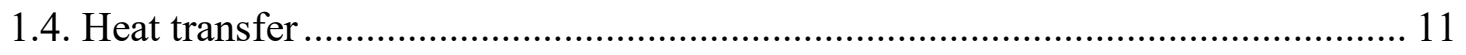

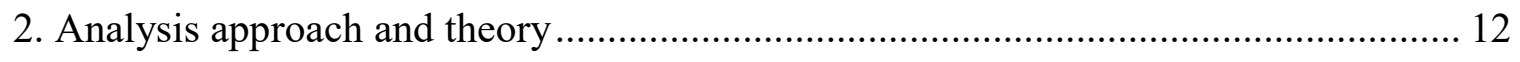

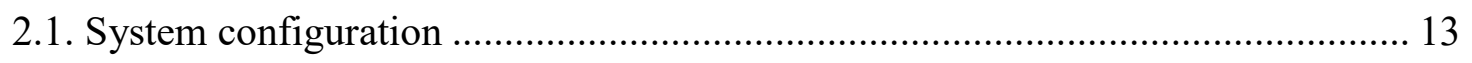

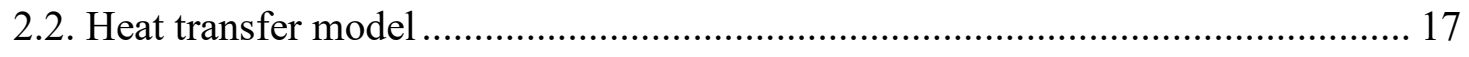

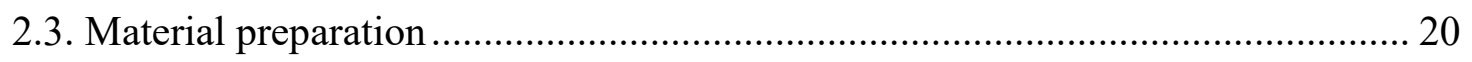

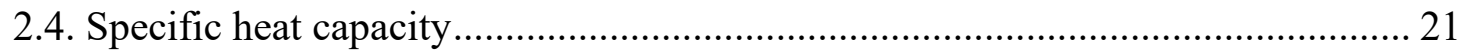

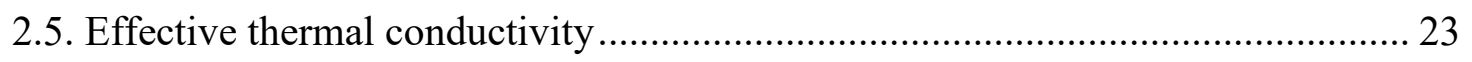

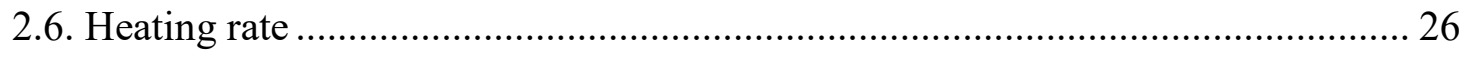


2.7. One dimensional model.

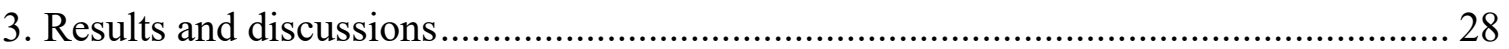

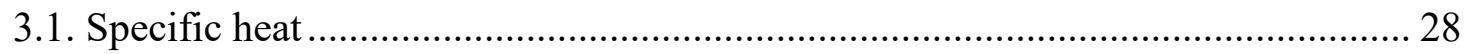

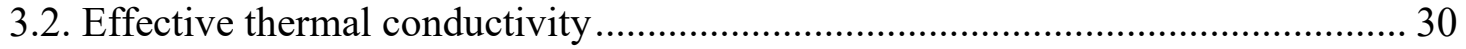

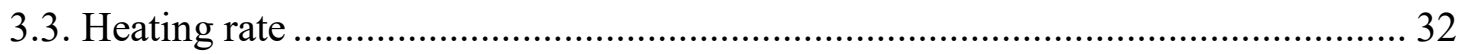

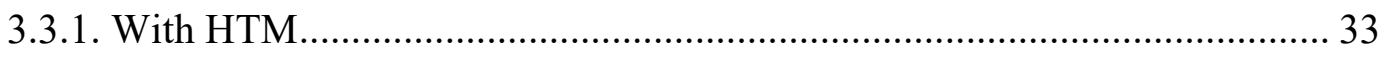

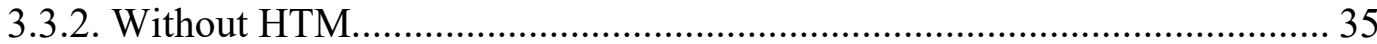

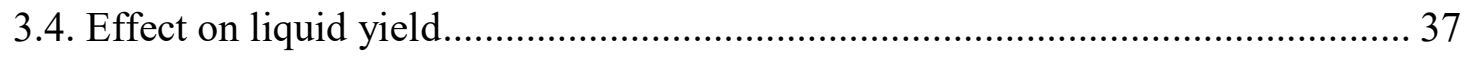

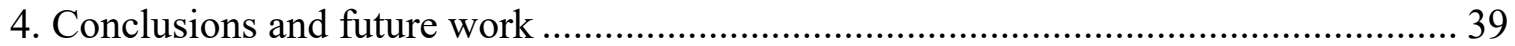

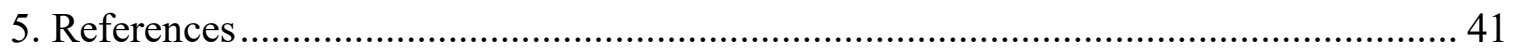




\section{List of figures}

Figure 1.1: Heat transfer mechanisms in a fluidized bed reactor................................... 5

Figure 1.2: Rotating cone fast pyrolyser setup. ................................................. 7

Figure 1.3: Detailed view of the rotating cone in a rotating cone fast pyrolyser.............. 8

Figure 1.4: Concept of ablative fast pyrolysis. ................................................... 8

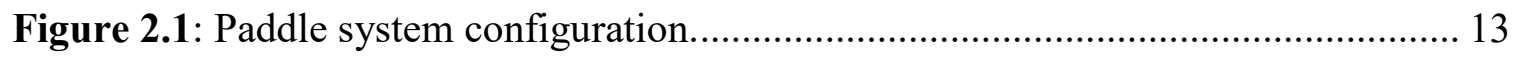

Figure 2.2: Schematics of the mixing paddle auger ............................................. 15

Figure 2.3: Location of heating elements in reactor. ................................................ 16

Figure 2.4: Typical set (dashed) and measured (solid) temperature gradient and heating

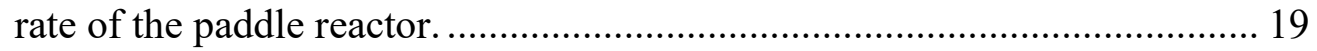

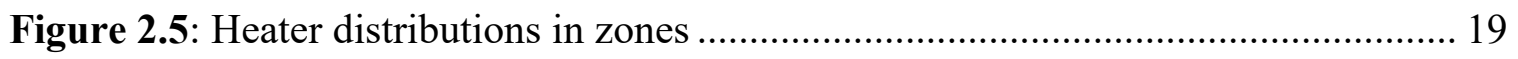

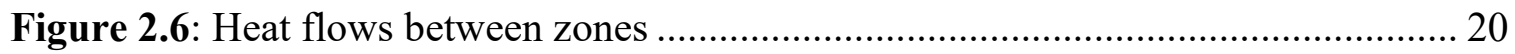

Figure 2.7: Net heating rate required to heat sand from ambient temperature to final

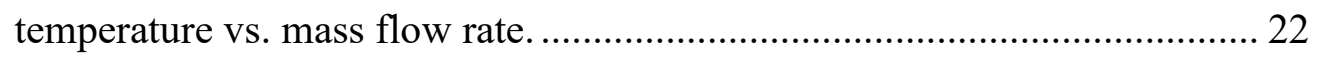

Figure 2.8: Net heating rate required to heat biomass from ambient temperature to final

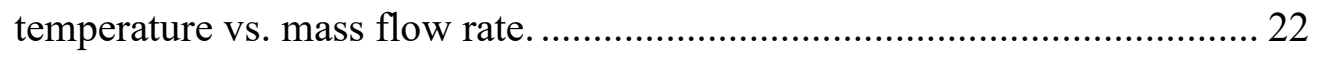

Figure 3.1: Determined specific heat of sand vs. temperature and comparison with NIST data. 29

Figure 3.2: Determined specific heat of biomass vs. temperature 29

Figure 3.3: Fitted $Q-$ Qloss vs. measured for sand for the temperature range $20^{\circ} \mathrm{C}$ $450^{\circ} \mathrm{C}$ and mass flow rate 0 to $3.6 \mathrm{~kg} / \mathrm{hr}$. 30 
Figure 3.4: Fitted $Q-$ Qloss vs. measured for biomass for the temperature range $20^{\circ} \mathrm{C}$ $300^{\circ} \mathrm{C}$ and mass flow rate 0 to $0.72 \mathrm{~kg} / \mathrm{hr}$. 30

Figure 3.5: Effective thermal conductivity of sand, keff, vs. solid volume fraction in reactor at the temperature range $50^{\circ} \mathrm{C}-450^{\circ} \mathrm{C}$. 31

Figure 3.6: Effective thermal conductivity of biomass, $k_{\text {eff }}$ vs. solid volume fraction in reactor at the temperature range $60^{\circ} \mathrm{C}-300^{\circ} \mathrm{C}$.

Figure 3.7: Temperature transient of fast pyrolysis of biomass (sawdust) with sand as HTM . 35

Figure 3.8: Heating rate transient for fast pyrolysis of biomass (sawdust) with sand as HTM

Figure 3.9: Heating rate vs solid volume fraction of biomass in the temperature range $75^{\circ} \mathrm{C}-125^{\circ} \mathrm{C}$

Figure 3.10: Experimental temperature profile for fast pyrolysis of torrefied pine forest residues without HTM 38

Figure 3.11: Liquid yield as predicted by the Klinger et al. model for various heating rates 38 


\section{List of tables}

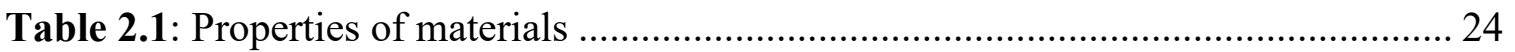

Table 3.1: Properties/parameters for one dimensional model ....................................... 34

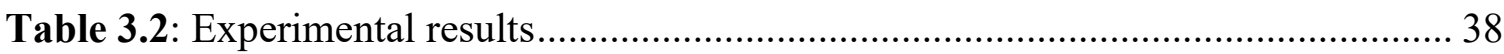




\section{Preface}

This master's thesis contains material previously reviewed and published in scientific journals. Full citation details for these works are given below

Reprinted with permission from

Ullal, A., Zinchik, S., Donepudi, Y., Klinger, J., Westover, T., \& Bar-Ziv, E. (2017). Heat transfer analysis in a paddle reactor for biomass fast pyrolysis. Manuscript submitted for publication to Fuel processing technology.

Author contributions:

Ullal - $\quad$ Experimental planning, collection of data, numerical modeling, analysis and interpretation of data, writing of the paper.

Zinchik - Experimental setup and planning, collection of data.

Donepudi - Experimental setup and planning, collection of data.

Klinger - Numerical modeling, analysis and interpretation of data, paper review and editing.

Westover - Experimental planning, analysis and interpretation of data, paper review and editing.

Bar-Ziv - Experimental planning, analysis and interpretation of data, paper review and editing. 


\section{Acknowledgements}

I would like to thank my thesis advisor Dr. Ezra Bar-Ziv and co-advisor Dr. Jordan Klinger for giving me this opportunity to participate in this research and guiding me throughout this work. The discussions and debates regarding research approaches we had, helped me deepen my understanding in the subject.

I would like to acknowledge Dr. David Shonnard, Dr. Jeffrey Naber and Dr. Tyler Westover for serving in my advisory committee and carefully reviewing this work.

I also greatly appreciate and thank our research group members Stas Zinchik and Yashwanth Donepudi for helping me conduct experiments and assisting me when in need. I did learn a lot from your expertise.

I would also like to acknowledge the contributions of Dr. Youngchul Ra in helping me understand concepts and providing insights into approaches in modeling and simulation studies. 


\section{Abstract}

Heat transfer analysis was performed on a novel auger reactor for biomass fast pyrolysis. As part of this analysis, correlations for specific heat capacity and heat transfer coefficients for biomass (sawdust) and sand (used as heat transfer medium) were developed. For sand, the heat transfer coefficient followed a power law distribution with reactor fill level and temperature. For raw biomass, the heat transfer coefficient also showed similar dependence on fill level, but was independent of temperature up to $300^{\circ} \mathrm{C}$. These correlations were used in a one dimensional heat transfer model developed to calculate the heating time and heating rate of biomass in the presence of a heat transfer medium (HTM). A heating time of 3 seconds was obtained to raise the temperature of biomass from $298 \mathrm{~K}$ to $753 \mathrm{~K}$. Instantaneous heating rates up to $530 \mathrm{~K} / \mathrm{s}$ were obtained, thus ensuring fast pyrolysis. Further, to study the effect of heating rates on liquid product yields, a previously validated torrefaction-pyrolysis model was used to calculate the liquid yields for torrefied pine forest residues at various heating rates. A threshold heating rate value of $12 \mathrm{~K} / \mathrm{s}$ was obtained from the model, above which the final product distribution was not affected. The model predicted liquid yield was $54 \%$, in comparison to the experimental yield of $53 \%$, for torrefied pine forest residues without HTM. The steady state experimental heating rate of $36 \mathrm{~K} / \mathrm{s}$ was observed, which was above the $12 \mathrm{~K} / \mathrm{s}$ threshold value thus ensuring fast pyrolysis. The results obtained in this paper will be used as a basis for scaling up the reactor configuration to carry out fast pyrolysis without HTM. 


\section{Introduction ${ }^{1}$}

In the last 4 decades alternative energy sources have gained considerable importance as uncontrolled use of fossil fuel has contributed to climate change. Important legislative measures by the United Nations such as the Kyoto protocol (United Nations, 1998) and the Paris agreement (United Nations, 2015) under the United Nations Framework Convention on Climate Change (UNFCCC) have forced nations to comply to regulations regarding the use of fossil fuel in order to control greenhouse gas emissions. Energy demand is increasing rapidly, the majority of it coming from developing countries, thus increasing environmental damage and contributing to global warming (Hafez \& Bhattacharya, 2012). This has led to renewable energy sources such as wind, solar and biomass being researched extensively. Among them, biomass energy sources are the only one which can produce solid, liquid and gaseous fuels (Bridgwater \& Peacocke, 2000). They can also be used as a drop-in fuel and use much of the fossil fuel infrastructure such as refineries, pipelines, gas stations which is already present (Muradov \& Veziroğlu, 2008). This has made them particularly an attractive option in comparison to other renewable energy sources. Majority of the biofuels currently in the market are first generation biofuels. They are derived from residues of crops, which are grown primarily on agricultural land. With growing need for food, this has put first generation fuels on the back foot. Due to this factor, research in biomass has shifted to second-generation fuels. These are grown in waste or fallow lands and do not compete with food crops in any way. Although many technologies exist in pilot scale for

\footnotetext{
${ }^{1}$ The material contained in this thesis is submitted for publication in Fuel processing technology
} 
the production of second generation biofuels, they are not yet largely commercialized due to economic reasons (Damartzis \& Zabaniotou, 2011). Biomass energy generation process can broadly be classified into thermochemical, chemical catalysis and biochemical processes (Damartzis \& Zabaniotou, 2011). Biochemical processes involve microorganisms breaking complex carbohydrates molecules into sugars. These sugars are then converted to alcohols by fermentation (Damartzis \& Zabaniotou, 2011). In contrast, chemical conversion technologies use inorganic catalysts to break down complex molecules into simpler ones. Thermochemical processes are in which heat is used to break down complex molecules. Combustion, gasification and pyrolysis are the major class of processes that fall under this section (Shaw, 2006). Among the thermochemical processes, this work concentrates on pyrolysis. We give a brief overview of pyrolysis in the following section.

\subsection{Fast pyrolysis}

By definition, pyrolysis is a thermal decomposition of biomass at high temperatures in the absence of oxygen. Pyrolysis process in general is mainly dictated by two important factors, namely a) the physical heat transfer and b) chemical kinetics (Shaw, 2006). The process begins with the external heat source increasing the temperature of the fuel. The increased temperature results in pyrolysis reactions, forming volatiles and char. These volatiles further transfer heat to unpyrolysed fuel, after which some of these volatiles condense to produce tar. They can also take part in secondary pyrolysis reactions (Shaw, 2006). Pyrolysis processes can be further classified as slow, fast or flash depending on 
process parameters such as temperature, vapor residence time and heating rates. Among these fast pyrolysis is suitable for obtaining the maximum liquid yield. The time scale of this process lies in the range of 1-5 seconds (Bridgwater, Meier, \& Radlein, 1999). The process parameters such as temperature, vapor residence time and heating rate have to be controlled (Bridgwater et al., 1999). In order to maximize liquid fuel yield, the process should have short gas phase residence time with high solid heating rates to prevent secondary reactions from altering the product composition. The char formed must be separated from the gas as they can catalyze secondary reactions (Bridgwater, 2012). The literature reports fast pyrolysis temperatures to be in the range of $670-920 \mathrm{~K}$ in fluidized bed reactors for maximizing liquid yield (Di Blasi, 1996). Separation of vapors and solids is followed by rapid cooling of vapors to liquid fraction, commonly referred to as "biooil". The non-condensable gases are cleaned and exited into the atmosphere. Over the years various reactor designs have been developed to satisfy fast pyrolysis requirements, each having their own advantages and disadvantages. We briefly see this in the following section.

\subsection{Reactor designs}

Bubbling fluidized bed reactors are the most commonly used as they have the ability to achieve fast heat transfer rates due to high solid density (Abdelmotalib, Youssef, Hassan, Youn, \& Im, 2015). For effective heat transfer relatively small particles sizes of 2-3 mm are used (Bridgwater, 2012). It is important to note though many small scale research reactors exist, many are difficult to scale up due to limitations in heat transfer capabilities. In contrast to this, fluidized bed technology has been researched extensively and 
successfully scaled up (Bridgwater, 2012). Figure 1.1 (IEABioenergyTask34, 2016) shows the various modes of heat transfer for a fluidized bed reactor. Hot fluidizing gas and hot tubes containing a mix of char/gas and air provide heat transfer through convection. Conduction heat transfer takes place through hot sand and hot walls. The oil yield for these reactors are approximately $70-75 \%$ on a dry feed basis (Bridgwater, 2012). Biomass feed rate, gas fluidization velocity, temperature and pressure are the operational parameters that must be controlled (Boateng, Daugaard, Goldberg, \& Hicks, 2007). The combination of gas fluidization velocity and biomass feed rate control the vapor residence time of the volatiles and the char particles in the reactor. There are many examples of fluidized beds, which have been built on a commercial scale. Union Fenosa have built a $200 \mathrm{~kg} / \mathrm{h}$ plant in Spain based on the design from University of Waterloo. Dynamotive have built a $100 \mathrm{t} /$ day and 200 t/day plants in Canada (Bridgwater, 2012) 


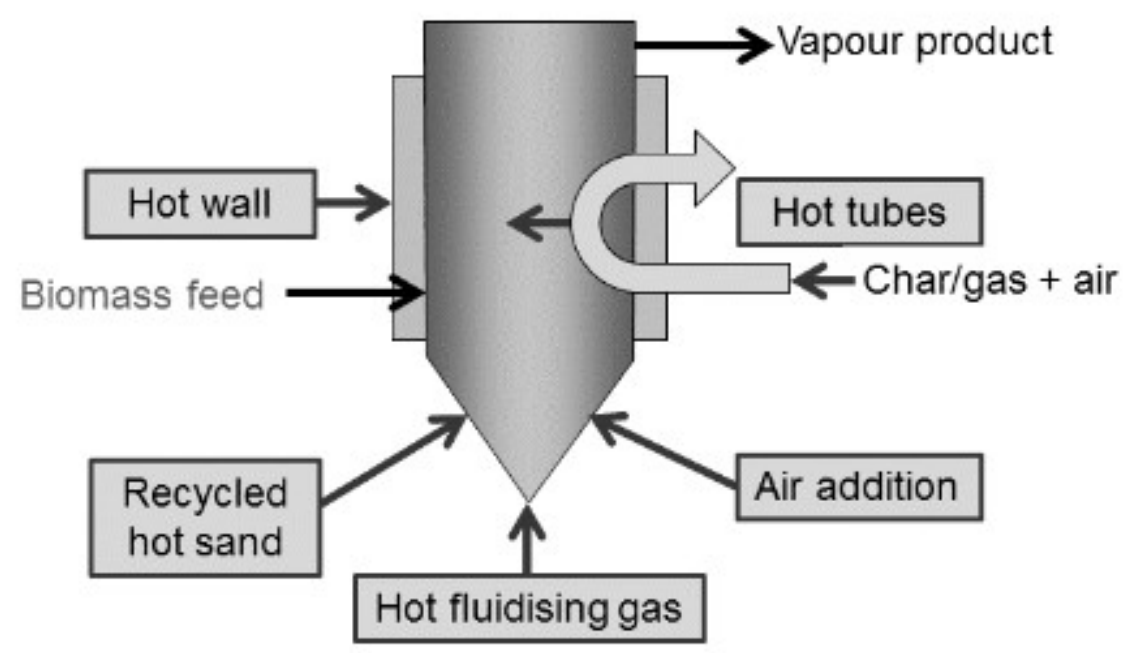

Figure 1.1: Heat transfer mechanisms in a fluidized bed reactor. ${ }^{2}$

Circulating fluidized bed (CFB) reactors are similar to bubbling fluidized beds, but they reuse inert heat transfer medium (HTM) by the use of gas separation cyclones. This is done by using high fluidization velocity to ensure all solid particles are driven into the gas cyclone separator. After passing the cyclone, the heat transfer medium (HTM) is reheated and recycled. Most reactor configurations use char produced from the process to heat the recycled sand through combustion. Thus CFB systems have a secondary combustion chamber to burn char produced (Trendewicz, Braun, Dutta, \& Ziegler, 2014). The unburnt fraction or ash has to be removed. Char is estimated to have $25 \%$ of the energy content of raw biomass (Brown, 2009). Thus utilization of char produced makes the overall process efficient. One of the major drawbacks of the fluidized bed technology is the requirement

\footnotetext{
${ }^{2}$ Reprinted with permission from IEABioenergyTask34. (2016). Reactors - Bubbling fluid beds. Retrieved from http://www.pyne.co.uk/? id=69
} 
of large carrier gas. The equipment's used to build these systems significantly increase capital and maintenance cost of these reactors (Aramideh, 2014).

The rotating cone reactor is a fast/flash pyrolysis reactor design developed by the University of Twente and the BTG group in Netherlands in 1993 (Bridgwater, 2012). Figure 1.2 (Bridgwater, 2012) shows the arrangement of a rotating cone pyrolyser. The heat transfer medium (HTM) and biomass are input at the bottom of the cone through a feeding system. The cone is rotated at a certain rpm using a motor. This rotation ensures very fast heat transfer from the HTM to the biomass particles. The vapors are then separated and condensed to produce bio oil. The solid particles (HTM \& char) being heavier are driven along the cone until they fall off from the top into a collection container below, where they can be recycled as shown in Figure 1.3 (Wagenaar, Kuipers, Prins, \& van Swaaij, 1993). Wagenaar et al. gives a more detailed description in their paper "The rotating cone flash pyrolysis reactor" (Wagenaar et al., 1993). Although the rotating cone pyrolyser uses no carrier gas it is still complex in design having many components. 


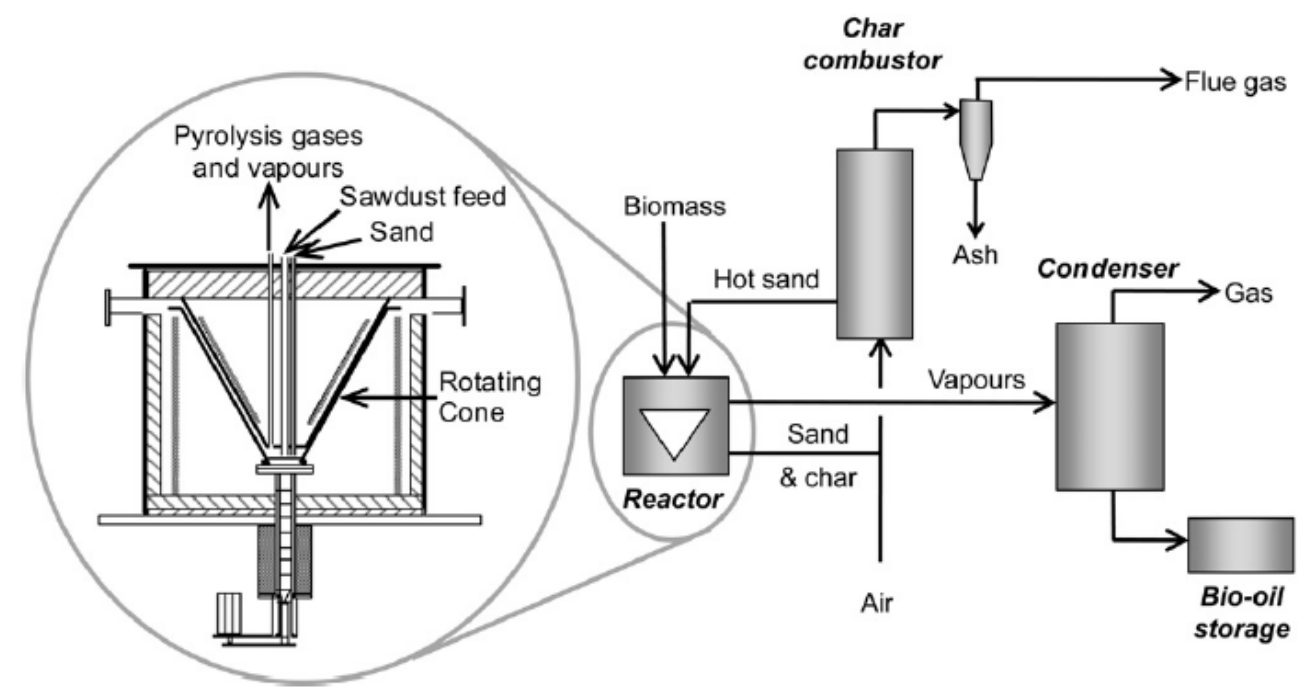

Figure 1.2: Rotating cone fast pyrolyser setup. ${ }^{3}$

Ablative pyrolysis reactor is another fast pyrolysis reactor concept in which particles are kept in contact with the heated walls through centrifugal force or by mechanical means. Figure 1.4 (Luo et al., 2017) shows an illustration of the concept. As the heat transfer is mainly through conduction, by contact of biomass particles under pressure with hot walls, very high heating rates are obtained. Thus, they do not require the presence of a heat transfer medium. These reactors also do not require fine particle size thus saving approximately $10-15 \%$ of the energy cost associated with grinding (Luo et al., 2017)

\footnotetext{
${ }^{3}$ Reprinted from Biomass and Bioenergy,Vol 38, A. V. Bridgwater, Review of fast pyrolysis of biomass and product upgrading, Pages No. 68-94, Copyright (2012), with permission from from Elseiver."
} 


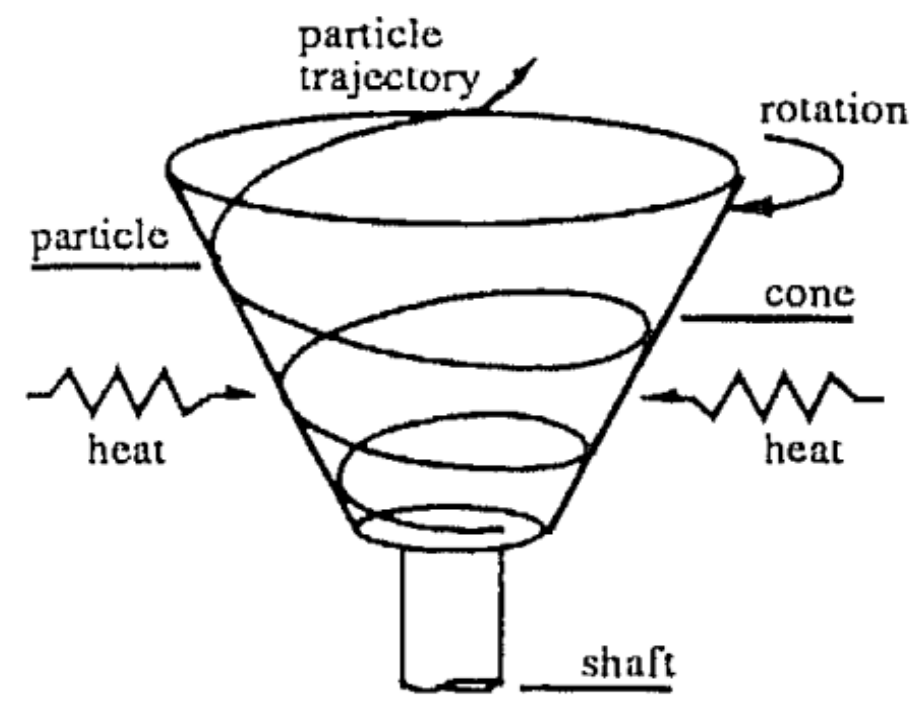

Figure 1.3: Detailed view of the rotating cone in a rotating cone fast pyrolyser. ${ }^{4}$

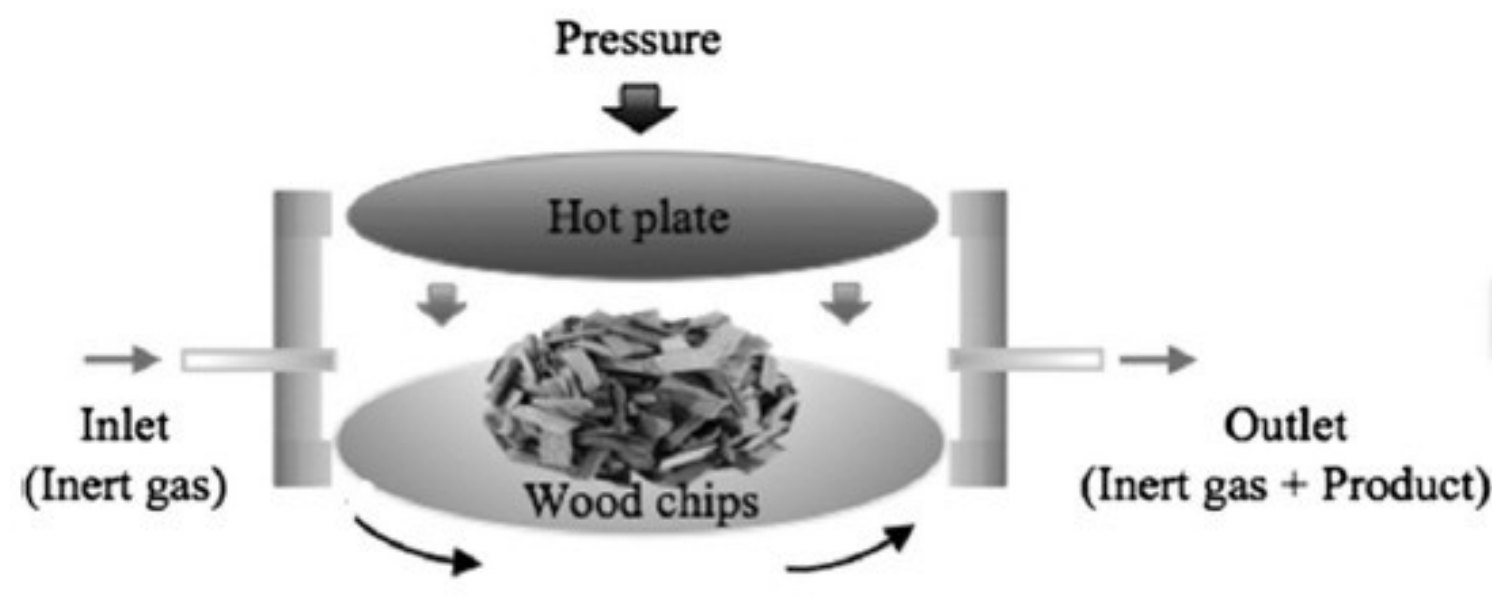

Figure 1.4: Concept of ablative fast pyrolysis. $^{5}$

\footnotetext{
4 "Springer Springerebook, The Rotating Cone Flash Pyrolysis Reactor, 1993, B. M. Wagenaar, Copyright 1993, "With permission of Springer"

5 “Reprinted from Fuel, Vol 194, Guanqun Luo, Devin S. Chandler, Luiz C.A. Anjos, Ryan J. Eng, Pei Jia, Fernando L.P. Resende, Pages No.229-238, Copyright (2017), with permission from Elsevier
} 
Although ablative pyrolysis requires no HTM or carrier gas and they can be used for any size distribution of particles, they are complex to design and difficult to scale up (Aramideh, 2014). Keeping in mind all factors explained in this section, it was decided to select the auger reactor design for our reactor. The following section provides a description and advantages of auger reactors.

\subsection{Auger reactors}

Augers were initially used in the coal industry back in the $20^{\text {th }}$ century. Until now they have been undergoing development to suit various processes such as drying, feeding, pyrolysis and extrusion (Roegiers, Pieters, \& Ronsse, 2016). The first augers were used to produce coke from coal through slow pyrolysis. They faced problems with coal residue (tar) being deposited on the auger surface thus reducing its conveying efficiency over time. On further investigation, it was found that, as these augers were externally heated, the colder material was often deposited on the shaft surface (Roegiers et al., 2016). In order to prevent this deposition and help scale up the process, a hollow heated shaft was used for the auger. In 1950, the Lurgi-Ruhrgas reactor was used to produce town gas from oil shale. This process used sand as a heat transfer medium to tackle the problem of material deposition. The vapor was then passed through a cyclone to separate the solid particles (Brown, 2009). Most auger based thermal treatment processes, thus use a heat transfer medium (HTM) which is generally an inert material such as silica sand, steel shots, calcium oxide or clay minerals such as bentonite and sepiolite (Henrich, Dahmen, Weirich, Reimert, \& Kornmayer, 2016). Young nam Chun et al. have carried out the pyrolysis of 
dried sludge in a screw and rotary kiln gasifier (Chun, Kim, \& Yoshikawa, 2011). In addition to this Henrich et al. have used the twin screw mixer for performing fast pyrolysis (Henrich et al., 2016). Augers have also been used in the waste disposal and recycling industries. Thermal degradation of waste tires was carried out by Day et al.(Day, Cooney, \& Shen, 1996). All the examples mentioned are indications of the versatile material handling capacity of auger systems.

Auger reactors for fast pyrolysis, although not commercialized are attractive due to their simplicity and robustness (Briens, Piskorz, \& Berruti, 2008). Unlike fluidized bed reactors, auger reactors do not require much gas for fluidization, which makes them compact. The associated equipment with fluidizing gas such as blowers and pumps are also not required therefore decreasing capital costs (Brown, 2009). They also require low energy requirements and it is easier to separate solid (char) and gas phases (Verma et al., 2011). These reactors can also be used to build portable pyrolysis systems for small plants (Veses et al., 2014). According to Puy et al., these reactors have excellent reproducibility (Puy et al., 2011). They can also be operated in continuous mode and show stable behavior. As mentioned in section 1.1, the vapor residence times is one of the critical requirements to ensure fast pyrolysis. Considering this fact auger reactors can have easy and precise vapor residence time adjustment by adjusting the length of the reactor or the speed of rotation of the auger (Mohan, Pittman, \& Steele, 2006). In addition to this auger reactors can operate at lower temperatures $\left(400^{\circ} \mathrm{C}\right)$ to ensure fast pyrolysis thus saving in operational costs (Mohan et al., 2006). The following section describes the motivation for having effective heat transfer requirements in fast pyrolysis systems. 


\subsection{Heat transfer}

Heat transfer analysis is an important task in designing a thermochemical process. Understanding the thermal behavior of the system is of primary importance in order to maintain optimal process control. In many commercialized industrial processes, this has been achieved by repeated experimentation over long periods of time. Currently, data from these experiments are used to develop simulation models, thus reducing the cost of design. This model based approach has become standard for various thermochemical processes in oil refineries, power and chemical industries.

Heat transfer models can depend on the complexity of the hydrodynamic models used to characterize the flow in the auger reactor. According to J Roegiers et al., the approaches used to describe hydrodynamics are Euler-Euler flow model, Euler-Lagrangian flow model and a mixture model (Roegiers et al., 2016). The Euler-Euler model considers the solid phase as a fluid. The heat transfer is modeled through an interface existing between both phases. The Euler-Lagrangian model considers the solid phase as particles interacting with the fluid. The mixture model solves only one set of Naiver-Stokes equations for the mixture and is not used for dense granular flows. Aramideh et al. have studied the heat transfer in the auger reactor for fast pyrolysis using the Euler-Euler model. In our study the EulerEuler model assumption is used as it offers the best compromise between accuracy and computational time (Aramideh, 2014).

Our fast pyrolysis system has an auger configuration with a novel design for the auger, consisting of a combination of cut flighting's and mixing paddles to increase heat transfer 
between the biomass and the heat transfer medium (HTM). Figure 2.2 shows a view of this design. This auger design also increases solid residence time and delays conveying capacity in comparison to a regular auger. This is an indication of good mixing among the biomass and heat transfer medium as shown in our previous work (Zinchik et al., 2017). As the cut flighting's and the mixer paddles have a unique configuration, it is expected that correlations from the literature will not be applicable and must be developed, which is one of the main objective of this thesis. For developing these correlations, thermal properties such as specific heat and heat transfer coefficients are necessary. These properties are required for both biomass as well as the heat transfer medium (HTM), which in our initial study is silica sand. Very little information was found in the literature regarding the variation of specific heat with temperature for biomass. Thus, a method has been developed to measure these properties using our reactor, which will be described in detail in the following sections. We also study the effect of heating rates, both with and without the presence of heat transfer medium (HTM) on fast pyrolysis of raw and torrefied biomass in addition to the effect of mixing on the heat transfer in this reactor. This gives important insight into the possibility of commercializing (scaling up) this reactor configuration.

\section{Analysis approach and theory}

This section describes the experimental setup and the approach followed to perform experiments in order to obtain the required thermal properties using our reactor setup. 


\subsection{System configuration}

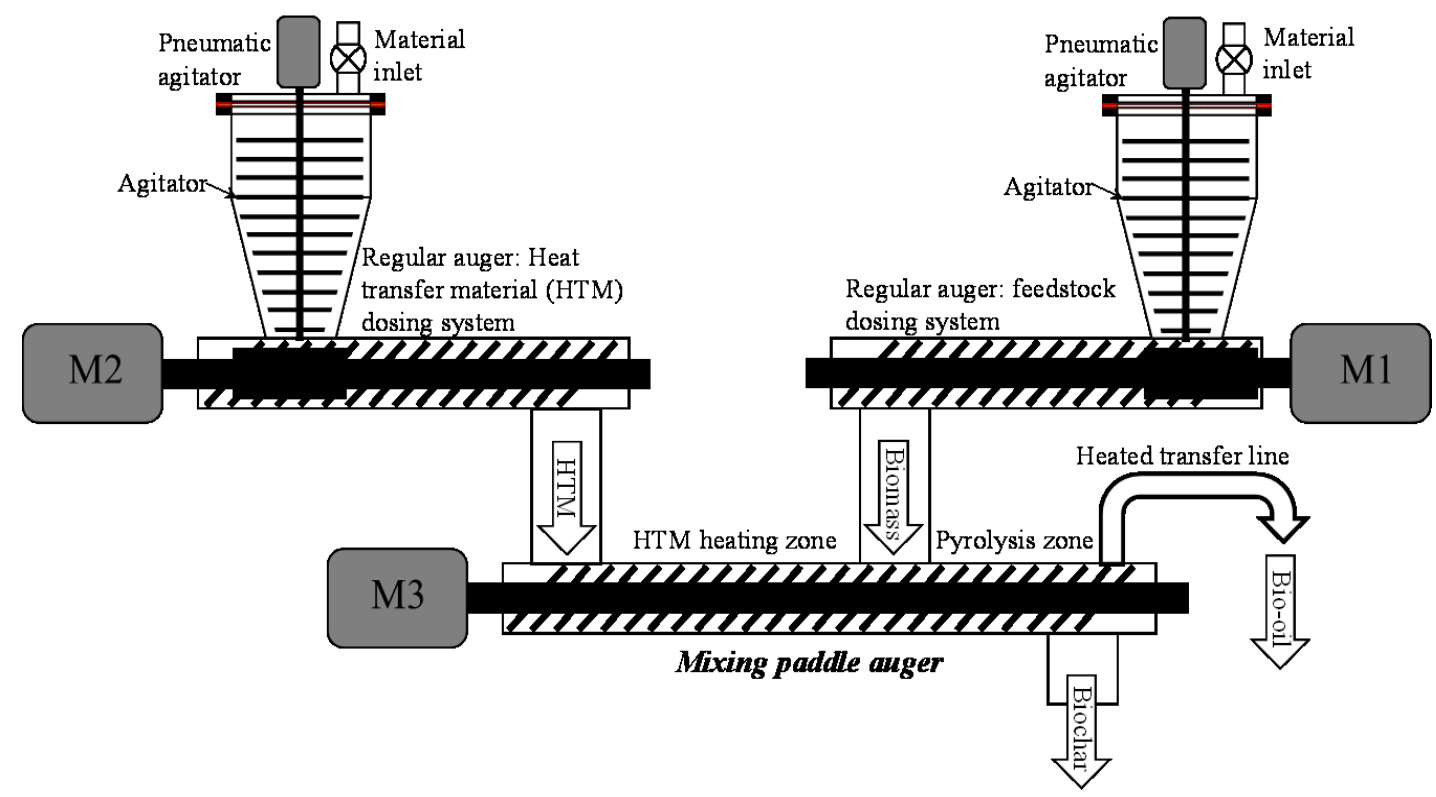

Figure 2.1: Paddle system configuration.

The schematic figure of the fast pyrolysis reactor system is shown above in Figure 2.1. It comprises of two feed bins, one for the HTM (heat transfer medium) dosing system and another for the feedstock dosing system. The shape of the feed bins is designed to ensure smooth flow of material to the mixing paddle auger reactor. A pneumatic agitation system is used in both feed bins to prevent bridging and ensure smooth flow of material into the reactor. The system was designed to perform fast pyrolysis experiments with HTM. When used in this configuration, the feed bin corresponding to M2 (refer Figure 2.1) is filled with HTM and the one corresponding to M1(refer Figure 2.1) is filled with biomass feedstock. The flow of HTM material from the feed bin to the mixing paddle auger reactor is control fed using a regular auger driven by a variable frequency drive motor (VFD) M2. Similarly, the feedstock is control fed into the reactor using a regular auger driven by a 
variable frequency motor (VFD) M1. As shown in Figure 2.1 the mixing paddle auger reactor can be divided into two zones, namely HTM heating zone and pyrolysis zone. In the HTM heating zone the temperature of the HTM is increased from room temperature to $550^{\circ} \mathrm{C}$. The hot HTM meets biomass feedstock at room temperature and fast pyrolysis takes place in the pyrolysis zone. The length of the HTM heating and pyrolysis zones are 12 and 6 inches respectively. In order to keep the system airtight, the feed bin openings are sealed with silica gel as shown (in red) in Figure 2.1. The mixing paddle auger is run by VFD motor M3. For all experiments, M3 was run at $200 \mathrm{rpm}$. By varying the speeds of M2 and M3, various solid filling fractions can be obtained in the mixing paddle reactor. The paddle auger with its unique design is shown in shown in Figure 2.2. The diameter of the auger used is 1 inch. The mass ratio of biomass and HTM can be controlled by varying the speeds of M1 and M2 respectively. The solid and gas fractions separate when they reach the end of the reactor. The solid fraction comprising of a mixture of char and HTM being heavier is collected in a container below. The gas vapors being lighter flow through a heated transfer line (refer Figure 2.1) into a two stage condensation system. The first stage is a water-circulated condenser, in which water is maintained between $10^{\circ} \mathrm{C}$ to $20^{\circ} \mathrm{C}$. The condenser used is a shell and tube heat exchanger, with gas vapors flowing within the tubes and water flowing around them. The second stage condensation system is an ice/water scrubber maintained between $5^{\circ} \mathrm{C}$ to $10^{\circ} \mathrm{C}$. The gas fraction remaining after this condensation system are considered as non-condensable gases. As this is only a demonstration setup, these gases are released into the atmosphere via an induced draft fan. The system is airtight, and flow is directed with a sweep stream of high-purity nitrogen. 


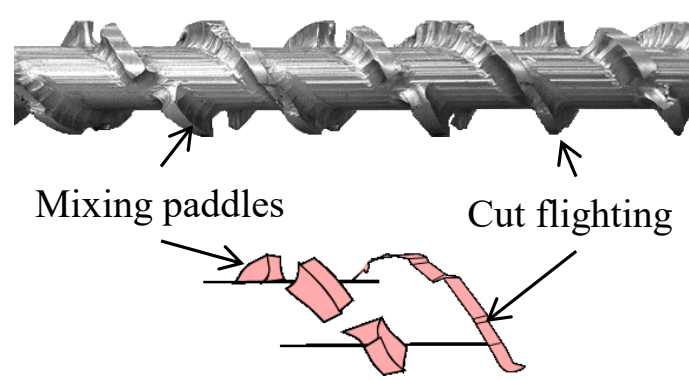

Figure 2.2: Schematics of the mixing paddle auger

Figure 2.3 shows the heat balance diagram as well as the location of the heaters along the length of the reactor. Each heater is a band heater having a power rating of $250 \mathrm{~W}$. The heaters operate with on-off control using a PID control loop such that their combination can maintain the reactor temperature according to the specified set temperature. Every heater is thus associated with a thermocouple. The thermocouples used were of the k-type (McMaster-Carr). The temperature for each heater is maintained with an independent PID control loop.

When running an experiment, in order to determine the thermal properties we use only the feed bin associated with M2 (refer Figure 2.1). The material whose thermal properties is to be measured is input into this feed bin and its flow rate into the paddle reactor is controlled by varying the speed of M2. The system is inerted with nitrogen flowing at a constant rate of approximately $0.25 \mathrm{~L} / \mathrm{min}$. The on/off duty cycles of all heaters is recorded when steady state is reached. Steady state is defined when the heating rate reading of all the heaters remain constant with time in the presence of a constant material flow rate. The 
sum of the heating duties gives the heat required to overcome the radial and axial heat losses, as well as the heat required to increase the temperature of the gas from ambient temperature up to the specified set temperature. After steady state is reached, the HTM material flow is input into the reactor by controlling the rotation speed of M2. Each rotation speed corresponds linearly to a mass flow rate as demonstrated through calibration and flow analysis performed in previous work (Zinchik et al., 2017). The heating duties are again recorded when steady state is reached. Note that nitrogen gas is flowing at the same constant flow rate as it was without the material. The difference in the power consumption (with and without material) directly gives the amount of energy required to heat the material from ambient to the specified set temperature.

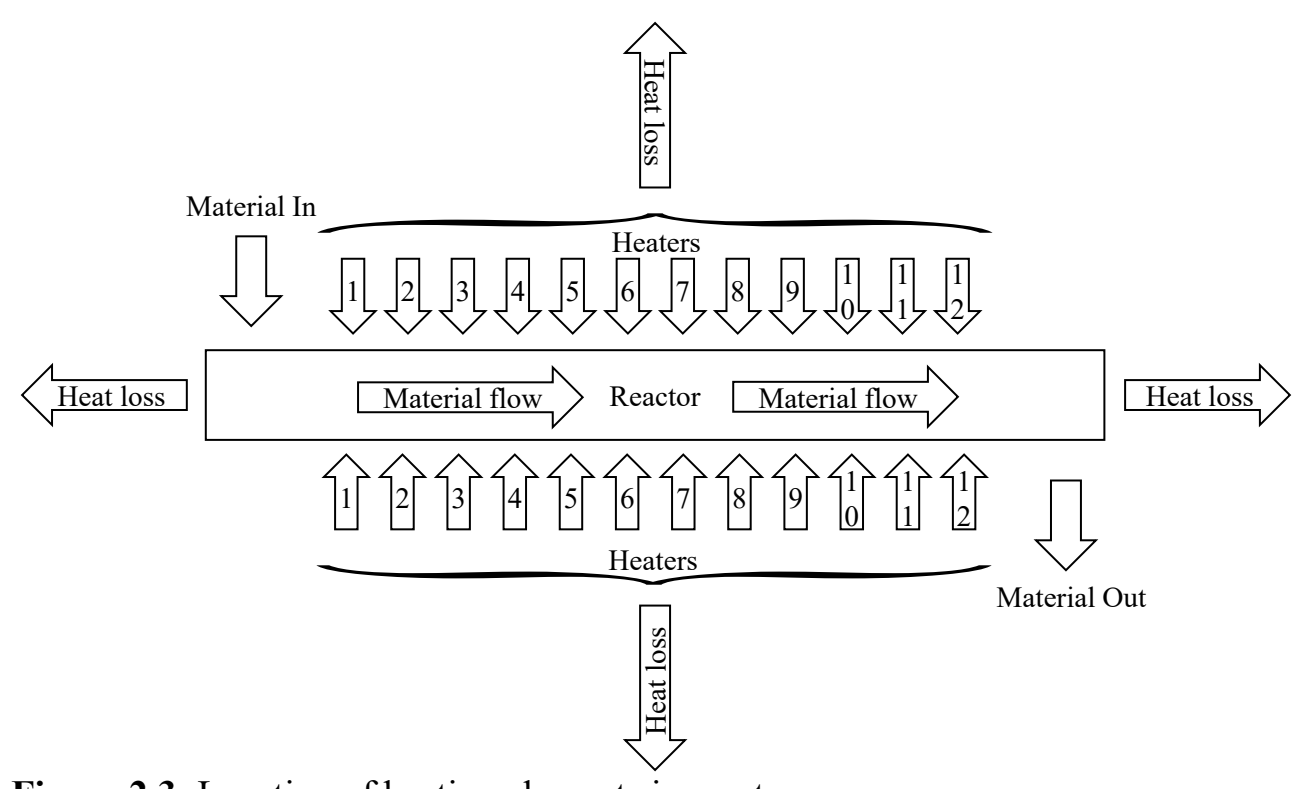

Figure 2.3: Location of heating elements in reactor. 


\subsection{Heat transfer model}

Due to the mixing and turbulent nature of the paddle auger reactor, the following assumptions are made for our heat transfer model:

1. Heat transfer takes place in the axial direction.

2. Material is considered as a continuum phase.

As the material flows along the length of the reactor with the mixer paddle auger running at a fixed speed (200 rpm), the heat transfer equation for a control volume can be generally written as (in the presence of an axial temperature difference $\Delta T$ ) shown below

$$
\dot{q}(\dot{m}, T, x)=h(\dot{m}, T) A \Delta T+\dot{m} \int_{T_{1}}^{T_{2}} c_{P}(T) d T
$$

eq. 1

Where $\dot{q}$ is the heating rate to raise the material from a temperature $T_{1}$ to a temperature $T_{2}$ and to overcome the heat transfer due to temperature difference $(\Delta T)$ across a specified control volume boundary. $A$ is the cross section area of the reactor, $\dot{m}$ is the material mass flow rate, $c_{p}$ is the specific heat capacity of the material, $T$ is the absolute temperature in $\mathrm{K}$ and $h$ is the heat transfer coefficient.

Figure 2.4 (top) shows an illustration of the set (dashed line) and measured (solid line) axial temperature difference along with the corresponding heating rates (bottom) of the heaters. In this particular case, the set temperatures corresponding to heaters $1-5$ were $50^{\circ} \mathrm{C}$ and heaters 6-10 were $100^{\circ} \mathrm{C}$. Note that only 10 heaters are used as heaters 11 and 12 
compensate only for the losses and are hence not shown in further analysis. The temperature gradient can be divided into zone 1 and 2 respectively as shown in Figure 2.4. This division of zones for the reactor is more clearly depicted in Figure 2.5. Each zone can then be considered as a control volume and eq. 1 can be applied for each of these control volumes. In Figure 2.6 we see the heat balances for each of these zones. Thus we can write the general energy balance eq. 1 specifically for zones 1 and 2 as follows

Zone 1:

Heat supplied by heaters 1 to $5\left(\dot{q}_{1}(\dot{m}, T, x)\right)+$ Heat coming from zone $2(h(\dot{m}, T) A \Delta T)=$ Heat absorbed by the material flowing to raise its temperature from $T_{0}$ to $T_{1}$ $\left(\dot{m} \int_{T_{0}}^{T_{1}} c_{P}(T) d T\right)$

Zone 2:

Heat supplied by heaters 6 to $10\left(\dot{q}_{2}(\dot{m}, T, x)\right)=$ Heat leaving zone $2(h(\dot{m}, T) A \Delta T)+$ Heat absorbed by the material flowing to raise its temperature from $T_{1}$ to $T_{2}\left(\dot{m} \int_{T_{1}}^{T_{2}} c_{P}(T) d T\right)$

With respect to Figure $2.4 T_{0}$ is $20^{\circ} \mathrm{C}$ (ambient temperature) and $T_{1}$ is $50{ }^{\circ} \mathrm{C}$ and $T_{2}$ is 100 ${ }^{\circ} \mathrm{C}$. 


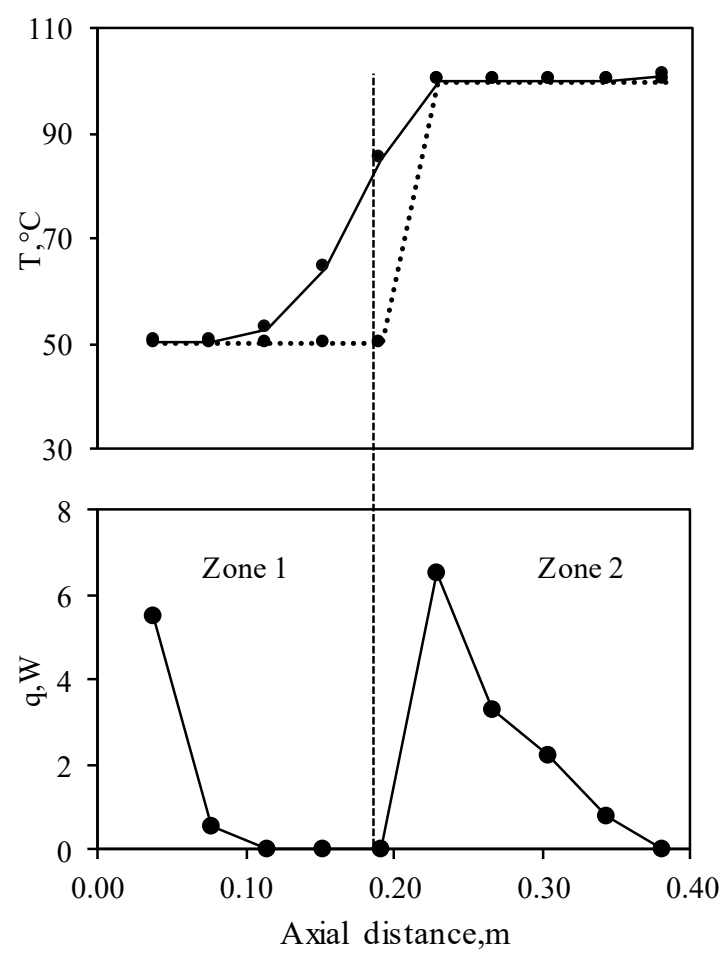

Figure 2.4: Typical set (dashed) and measured (solid) temperature gradient and heating rate of the paddle reactor.

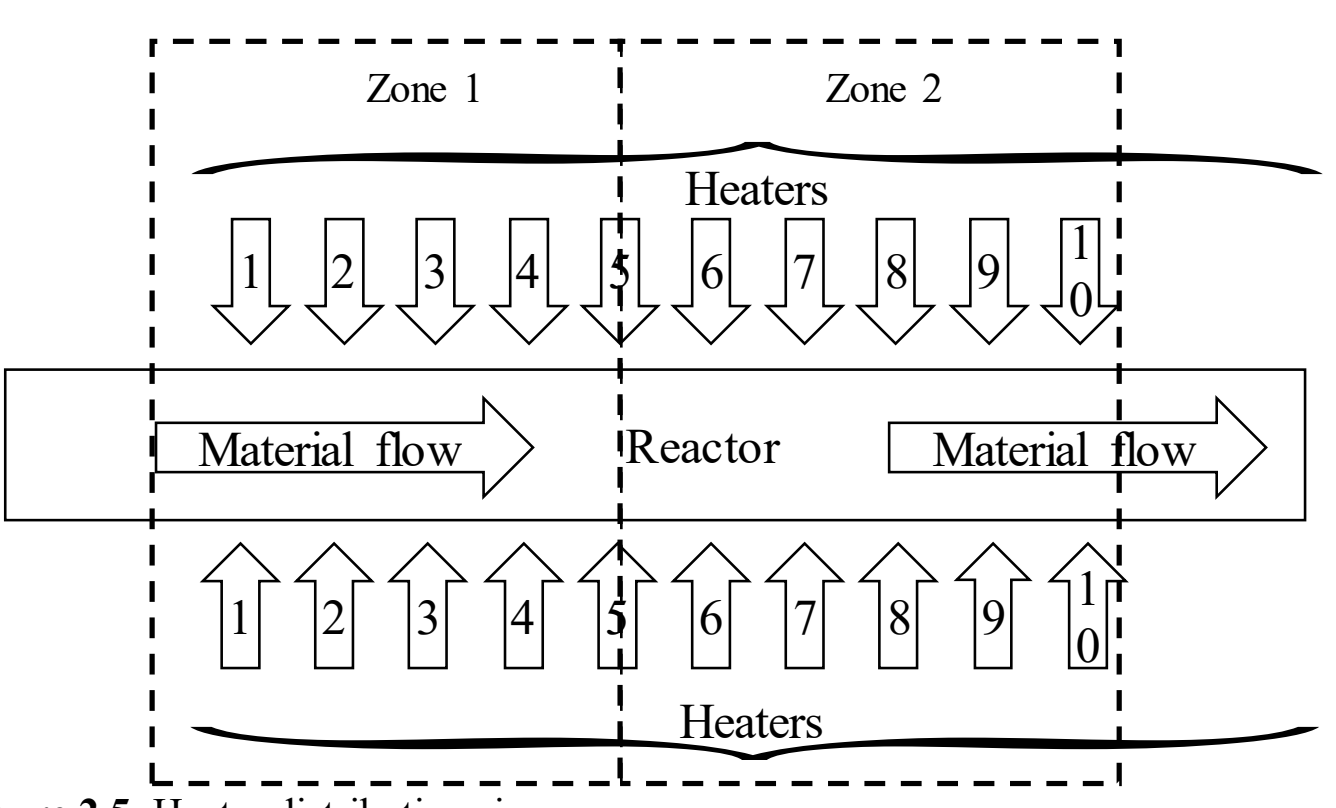

Figure 2.5: Heater distributions in zones 


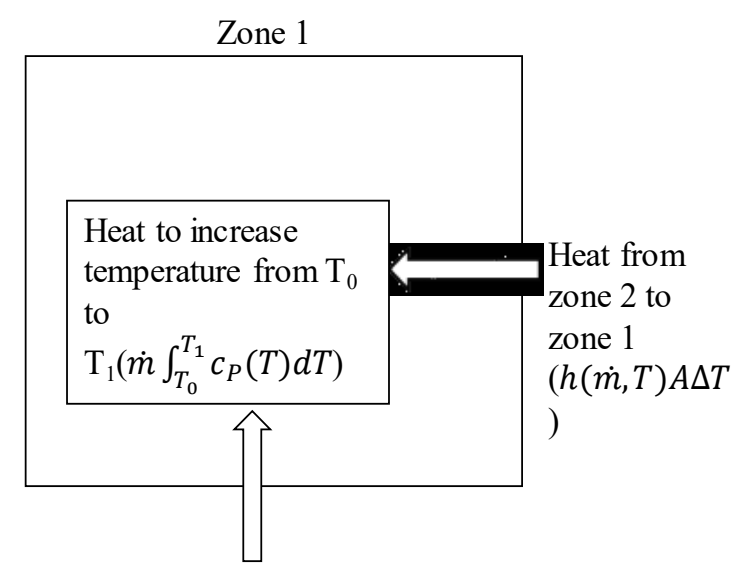

Heat from

heaters $1-5$

$\left(\dot{q}_{1}(\dot{m}, T, x)\right)$

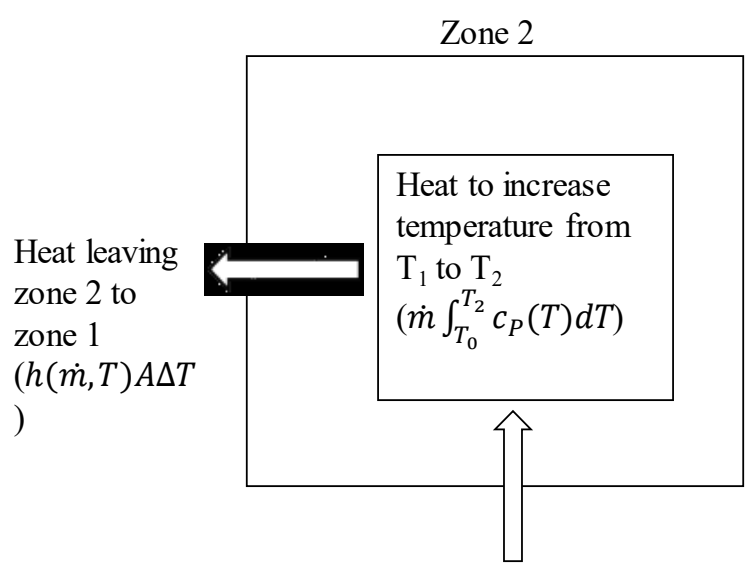

Heat from heaters 6-10 $\left(\dot{q}_{2}(\dot{m}, T, x)\right)$

Figure 2.6: Heat flows between zones

\subsection{Material preparation}

For the heat transfer analysis in this study, mixed hardwood sawdust was used as biomass and silica sand was used as the heat transfer medium (HTM). Washed silica sand commercially available was dried for 4 hours at a temperature of $150^{\circ} \mathrm{C}$. The sand mixture is then sieved for size fraction less than 450 micrometers. This ensured consistent size and flow properties within the reactor. The biomass used in our experiments was mixed hardwood sawdust locally available from a lumber mill. The sawdust was initially dried for around 4 hours at approximately $105^{\circ} \mathrm{C}$ in thin layers. After drying, the sawdust was sieved similar to the silica sand to a size distribution between 450-850 micrometers. 


\subsection{Specific heat capacity}

The temperature dependence of specific heat capacity is an important factor to consider when performing thermal analysis. In this study, the specific heat capacity of biomass (sawdust) and silica sand was measured over a range of flow rate and temperature conditions. As mentioned in section 2.1, the experiments are carried out, and the total heating rate values were recorded by a local computer/PLC. Figure 2.7 and Figure 2.8 show the variation of heating rate with mass flow rate for both sand and biomass respectively at two different temperature ranges. Linear behavior of heating rate with mass flow rate is observed for both materials. In Figure 2.7, all heaters were set to $100^{\circ} \mathrm{C}$ and $200^{\circ} \mathrm{C}$ in the $20^{\circ} \mathrm{C}-100^{\circ} \mathrm{C}$ and $20^{\circ} \mathrm{C}-200^{\circ} \mathrm{C}$ case respectively. In Figure 2.8 , for $150^{\circ} \mathrm{C}-$ $200^{\circ} \mathrm{C}$ case, heaters $1-5$ were set to $150^{\circ} \mathrm{C}$ and heaters $6-10$ were set to $200^{\circ} \mathrm{C}$. Similarly, for the $250^{\circ} \mathrm{C}-300^{\circ} \mathrm{C}$ case, heaters $1-5$ were set to $250^{\circ} \mathrm{C}$ and heaters $6-10$ were set to $300^{\circ} \mathrm{C}$. In all these cases summation of heating duties of all 10 heaters would provide the heat required to raise the temperature from $20^{\circ} \mathrm{C}$ to the set temperature (i.e. $100^{\circ} \mathrm{C} \& 200^{\circ} \mathrm{C}$ in Figure 2.7, $200^{\circ} \mathrm{C} \& 300^{\circ} \mathrm{C}$ in Figure 2.8). The heating rate required also increases as expected for higher temperatures. 


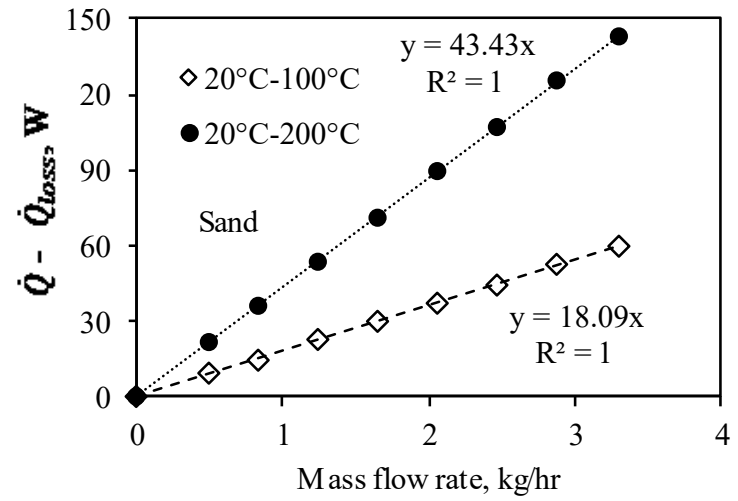

Figure 2.7: Net heating rate required to heat sand from ambient temperature to final temperature vs. mass flow rate.

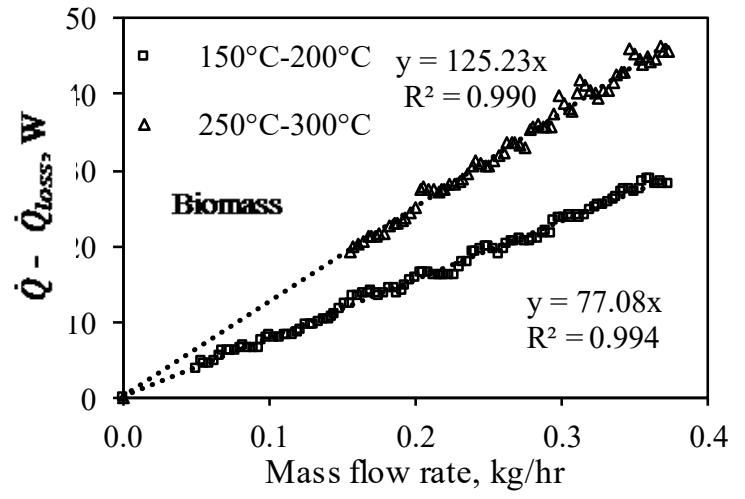

Figure 2.8: Net heating rate required to heat biomass from ambient temperature to final temperature vs. mass flow rate.

For this analysis, the heat of reaction and the effects of changing biomass composition are lumped into the heat capacity and are not considered independently.

As the analysis is performed on the material at thermal steady-state, eq. 1 is simplified to

$$
\dot{q}(\dot{m}, T)=\dot{m} \int_{T_{o}}^{T_{2}} c_{p}(T) d T
$$

Where $T_{o}$ is the ambient temperature and $T_{2}$ is the final set temperature (i.e. $100^{\circ} \mathrm{C} \& 200^{\circ} \mathrm{C}$ in Figure 2.7, $200^{\circ} \mathrm{C} \& 300^{\circ} \mathrm{C}$ in Figure 2.8). It is observed that, for many materials, the specific heat capacity is dependent on the square root of the absolute temperature. Thus, for the determination of the temperature dependence of $c_{p}$, it was assumed in this work that $c_{p}$ varies with temperature as $c_{P}=c \sqrt{T}$ where $c$ is a proportionality constant. Incorporating this relation into eq. 2 yields 


$$
\dot{q}(\dot{m}, T)=\dot{m} c \frac{2\left(T_{2}^{3 / 2}-T_{o}^{3 / 2}\right)}{3}
$$

Thus, the variation of specific heat capacity with temperature can be determined empirically through fitting of the constant $c$.

\subsection{Effective thermal conductivity}

It was observed from experiments that the heat transfer across well-defined length, $h \Delta x$, varies with solid volume fraction $\emptyset$ in the reactor and the temperature T. Here $\Delta x$ was taken as the diameter of the reactor.

The term $h \Delta x$ is referred to as "effective thermal conductivity $\left(k_{e f f}\right)$ ". "Effective thermal conductivity $\left(k_{e f f}\right)$ " can be thought of as the heat transferred in axial direction per unit area in the presence of a unit temperature gradient. It was previously shown, that the mixing behavior of the paddle auger reactor depends on the amount of material in the reactor, which in-turn follows a power-law relation to the operating conditions (Zinchik et al., 2017). Thus it is hypothesized that the effective thermal conductivity depends on the solid filling fraction $(\varnothing)$ and the absolute temperature $(T)$ in a similar relation. The effective thermal conductivity was assumed to follow:

$$
k_{e f f} \propto \emptyset^{n} T^{m}=A \emptyset^{n} T^{m}
$$

Where $n, m$ and $A$ are constants. The filling fraction $\emptyset$ is defined as the ratio of the volume occupied by the solid material particles to that of the total reactor volume. 


$$
\emptyset=\frac{V_{S}}{V_{R}}
$$

eq. 5

where $V_{R}$ is total reactor volume and $V_{S}$ is the solid volume

$$
V_{s}=\frac{\dot{m} t_{r e s}}{\rho_{m}}
$$

eq. 6

$\dot{m}$ is the material mass flow rate, $\rho_{m}$ is the intrinsic material density, $t_{r e s}$ is the material (solid) residence time in the reactor. In this study the intrinsic material density was assumed to change only slightly as the wood degrades, as was taken as an average constant value. Solid residence time determination has been carried out previously, and is given respectively for biomass and sand at $200 \mathrm{rpm}$ by eq. 7 and eq. 8 below (Zinchik et al., 2017)

$$
\begin{array}{ll}
t_{\text {res }}(\min )=0.68(\text { feed } r p m)^{-0.25} & \text { eq. } 7 \\
t_{\text {res }}(\min )=0.83(\text { feed } r p m)^{-0.62} & \text { eq. } 8
\end{array}
$$

Table 2.1 shows the properties and constants used in the above expressions

Table 2.1: Properties of materials

\begin{tabular}{|l|l|}
\hline Quartz density (intrinsic) (Haynes, 2012) & $2650 \mathrm{~kg} / \mathrm{m}^{3}$ \\
\hline $\begin{array}{l}\text { Wood density (intrinsic) (Rabier et al., } \\
2006)\end{array}$ & $1000 \mathrm{~kg} / \mathrm{m}^{3}$ \\
\hline Reactor cross section area & $0.000475 \mathrm{~m}^{2}$ \\
\hline Reactor volume & $0.000214 \mathrm{~m}^{3}$ \\
\hline
\end{tabular}


For analysis purposes we divided, the heater zones into zone 1 and 2 respectively (refer Figure 2.4). In the presence of an axial temperature gradient, the heat balance equation for the two zones can be written, as shown below.

Zone 1 , heaters $1-5$. If the total heating rate of heaters $1-5$ is represented by $\dot{q}_{1}$, and $\dot{q}^{\prime}$ represents the heating rate conducting backward from zone 2 to zone 1 , then

$$
\dot{q}^{\prime}+\dot{q}_{1}=\dot{m} \int_{T_{o}}^{T_{1}} c_{p} d T
$$

where $T_{o}$ is the ambient temperature and $T_{1}$ is the first temperature step $\left(50^{\circ} \mathrm{C}\right.$ in Figure 2.4).

Zone 2 , heaters $6-10$. If the heating rate by these heaters is similarly represented as $\dot{q}_{2}$ and $\dot{q}^{\prime}$ is the rate of heat leaving this zone, then

$$
k_{e f f} A \frac{\Delta T}{\Delta x}=\dot{m} \int_{T_{1}}^{T_{2}} c_{p} d T+\dot{q}^{\prime}
$$

$q_{2}$ provides the heat to raise the temperature from $T_{1}$ to $T_{2}$ as well as the heat that leaves zone $2\left(\dot{q}^{\prime}\right)$. Then,

$$
\dot{q}_{2}=\dot{q}^{\prime}+\dot{m} \int_{T_{1}}^{T_{2}} c_{p} d T
$$

where $T_{1}$ is the first temperature step $\left(50^{\circ} \mathrm{C}\right.$ in Figure 2.4) and $T_{2}$ is the second temperature step $\left(100^{\circ} \mathrm{C}\right.$ in Figure 2.4). From eq. 10 and eq. 11 


$$
k_{e f f} A \frac{\Delta T}{\Delta x}=\dot{q}_{2}
$$

$\dot{q}_{2}$ is measured from experiments. Note that in the case of biomass, $\dot{q}_{2}$ is the value after subtracting the heat due to moisture. Effective thermal conductivity can then be given by

$$
k_{e f f}=\frac{\dot{q}_{2}}{A} \frac{\Delta x}{\Delta T}
$$

\subsection{Heating rate}

Heating rate is one of the important considerations for ensuring fast pyrolysis. According to Onay, the maximum yield of 54\% was obtained for the fast pyrolysis of safflower seed in a fixed bed reactor having a heating rate of $300^{\circ} \mathrm{C} / \mathrm{min}$. The sweeping gas flow rate of $100-\mathrm{cm}^{3} \mathrm{~min}^{-1}$ was maintained in this experiment (Onay, 2007). Debdoubi et al. examined the oil yield at heating rates of 50,150 and $250^{\circ} \mathrm{C} / \mathrm{min}$ for the fast pyrolysis of esparto conducted in a fixed bed reactor, and found the maximum oil yield at a heating rate of $250^{\circ} \mathrm{C} / \mathrm{min}$ (Debdoubi, El amarti, Colacio, Blesa, \& Hajjaj, 2006). Di Blasi reports there is little effect on the final liquid yield distribution of fast pyrolysis products, if the heating rate is greater than $15 \mathrm{~K} / \mathrm{s}$ in thermally thin particles (Di Blasi, 1996). Previous work has shown that the axial position of material in the reactor is consistent and linear with time (Zinchik et al., 2017). Thus axial velocity $v$ can be given by

$$
v=\frac{\text { reactor length }}{\text { residence time }}
$$


From experiments the spatial temperature gradient $\frac{d T}{d x}$ is measured, which is then converted to rate of heating by multiplying with the constant axial velocity.

$$
\frac{d T}{d t}=v \frac{d T}{d x}
$$

The same equations can be used for experiments without the use of HTM.

\subsection{One dimensional model}

Using the specific heat and effective thermal conductivity concepts described in the previous sections, we describe a simple transient heating model. Keeping in mind the assumptions for the one-dimensional heat transfer model between sand and biomass as mentioned in section 2.2, the sand and biomass continuum are assumed to have a uniform temperature function with respect to time $(t)$ and are represented as $T_{s}(t)$ and $T_{b}(t)$ respectively.

The energy balance for sand and biomass can be written respectively as

$$
\begin{aligned}
& \rho_{s} c_{p s} V_{s} \frac{d T_{s}(t)}{d t}=\dot{E}_{s, \text { in }}-\dot{E}_{s, \text { out }} \\
& T_{s}(0)=823 \mathrm{~K} \\
& \rho_{b} c_{p b} V_{b} \frac{d T_{b}(t)}{d t}=\dot{E}_{b, \text { in }}-\dot{E}_{b, \text { out }}+\dot{E}_{g} \\
& T_{b}(0)=298 \mathrm{~K}
\end{aligned}
$$


where $\rho_{s}$ is the bulk density of sand, $c_{p s}$ is the specific heat capacity of sand, $V_{s}$ is the sand phase volume. $\dot{E}_{s, \text { in }}$ and $\dot{E}_{s, \text { out }}$ is the energy rate gained and lost by the sand phase respectively. As sand, only loses heat to biomass without gaining any $\dot{E}_{s, \text { in }}=0$ (Note in experiments, heaters are provided to compensate for external heat losses). $\rho_{b}$ is the bulk density of biomass, $c_{p b}$ is the specific heat capacity of biomass, $V_{b}$ is the biomass phase volume fraction. $\dot{E}_{b, \text { in }}$ and $\dot{E}_{b, \text { out }}$ is the energy rate gained and lost by the biomass phase respectively. As biomass is never hotter than the sand or the reactor body, $\dot{E}_{b, \text { out }}=0$ within the system. It is assumed that the energy generation term $\dot{E}_{g} \sim 0$.

The heat transfer from the sand, initially at $823 \mathrm{~K}$ to biomass, initially at $300 \mathrm{~K}$ can be given as a conduction equivalent term as follows

$$
\dot{E}_{b, \text { in }}=\dot{E}_{s, \text { out }}=K_{e f f} A \frac{\left(T_{s}(t)-T_{b}(t)\right)}{l_{c}}
$$

Where $A$ is the reactor cross-section area, $l_{c}$, the characteristic length (radius of reactor). $K_{\text {eff }}$ is the effective thermal conductivity for the mixture of sand and biomass.

\section{Results and discussions}

\subsection{Specific heat}

The experiments were carried out as explained in section 2.1 for both biomass and sand. Using the analysis from section 2.4 , the following co-relations for the specific heat capacity was obtained 
For sand

$$
c_{p}(T)=44.4 \sqrt{T}
$$

For biomass (sawdust)

$$
c_{p}(T)=78.8 \sqrt{T}
$$

Figure 3.1 and Figure 3.2 show the variation of specific heat capacity with temperature for sand and biomass respectively. It is observed that the calculated $c_{p}$ variation for sand has very good agreement with specific heat capacity data for quartz from NIST (NIST). Biomass $c_{p}$ values from the literature typically range from 1300-2000 J/kgK (Dupont, Chiriac, Gauthier, \& Toche, 2014). Our predicted values lies within the range observed in other published works.

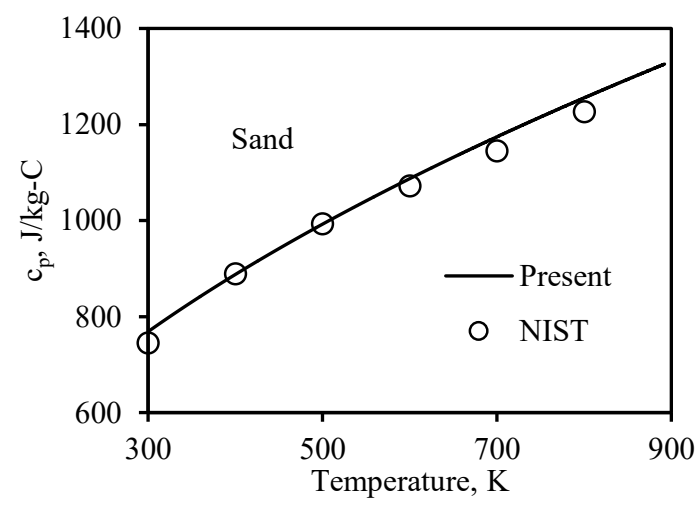

Figure 3.1: Determined specific heat of sand vs. temperature and comparison with NIST data.

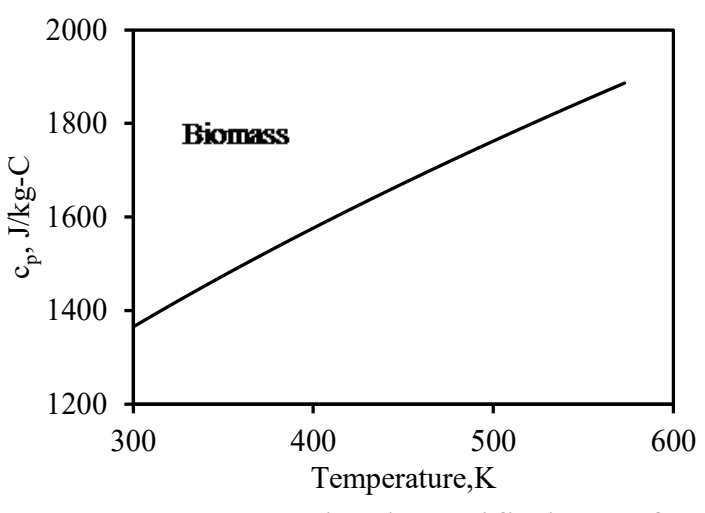

Figure 3.2: Determined specific heat of biomass vs. temperature 


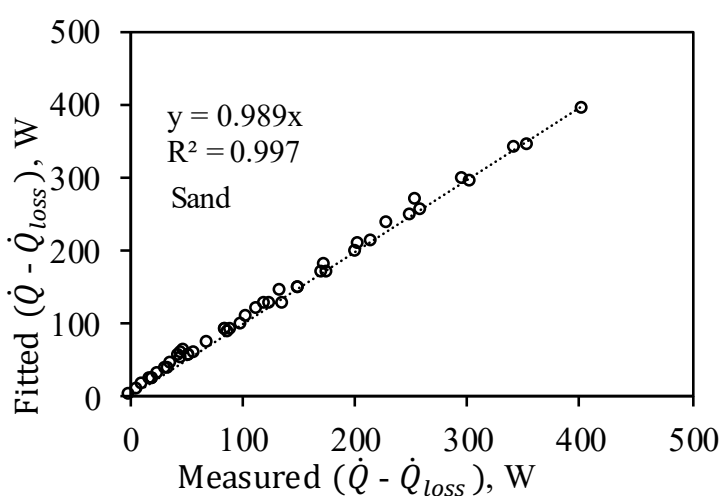

Figure 3.3: Fitted $\left(\dot{Q}-\dot{Q}_{\text {loss }}\right)$ vs measured for sand for the temperature range $20^{\circ} \mathrm{C}-450^{\circ} \mathrm{C}$ and mass flow rate 0 to $3.6 \mathrm{~kg} / \mathrm{hr}$.

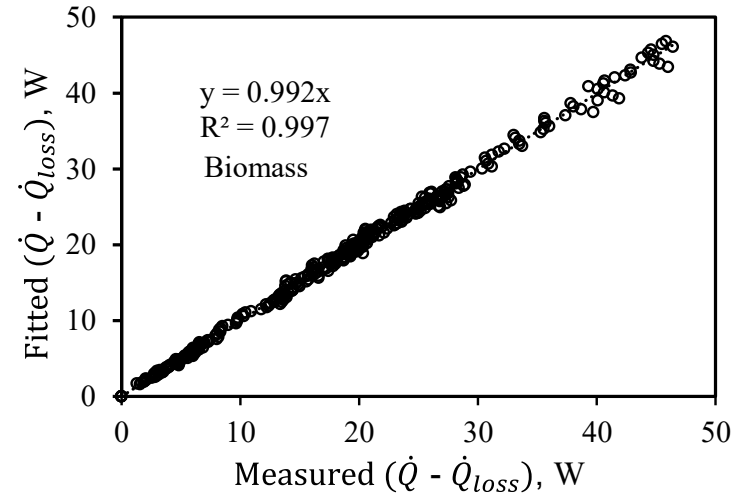

Figure 3.4: Fitted $\left(\dot{Q}-\dot{Q}_{\text {loss }}\right) \quad$ vs. measured for biomass for the temperature range $20^{\circ} \mathrm{C}-300^{\circ} \mathrm{C}$ and mass flow rate 0 to $0.72 \mathrm{~kg} / \mathrm{hr}$.

Substituting eq. 19 and eq. 20 in eq. 2 , the calculated heat supplied was plotted vs. the measured total heat supplied in Figure 3.3 and Figure 3.4 for sand and biomass. It is seen that there is very good agreement in the results between measured and fitted values. This is an indication of the accuracy of measurement of specific heat. These correlations for specific heat are used in the subsequent sections of thermal analysis.

\subsection{Effective thermal conductivity}

Using eq. 12, the effective thermal conductivity is calculated and plotted vs. solid volume fraction for both sand and biomass respectively as shown in Figure 3.5 and Figure 3.6.

From Figure 3.5, it is seen that the effective thermal conductivity for sand increases with volume fraction and temperature. This indicates that the effective thermal conductivity, or heat transfer in general, is enhanced with higher temperatures and filling levels. Solid 
volume fraction is proportional to the mass flow rate from its definition in section 2.5. Thus as mass flow rate increases, the heaters provide more heat to keep up with the specified set temperature which results in greater conduction through the same reactor cross section area per unit temperature gradient. It is also observed from Figure 3.5, that the effective thermal conductivity values increase with temperature for a given volume fraction. The magnitude of increase is greater at higher solid volume fractions. Non-linear regression of eq. 4 with the obtained $k_{e f f}$ data for sand yields

$$
k_{\text {eff }}=11,464 \emptyset^{3.64} T^{1.52}
$$
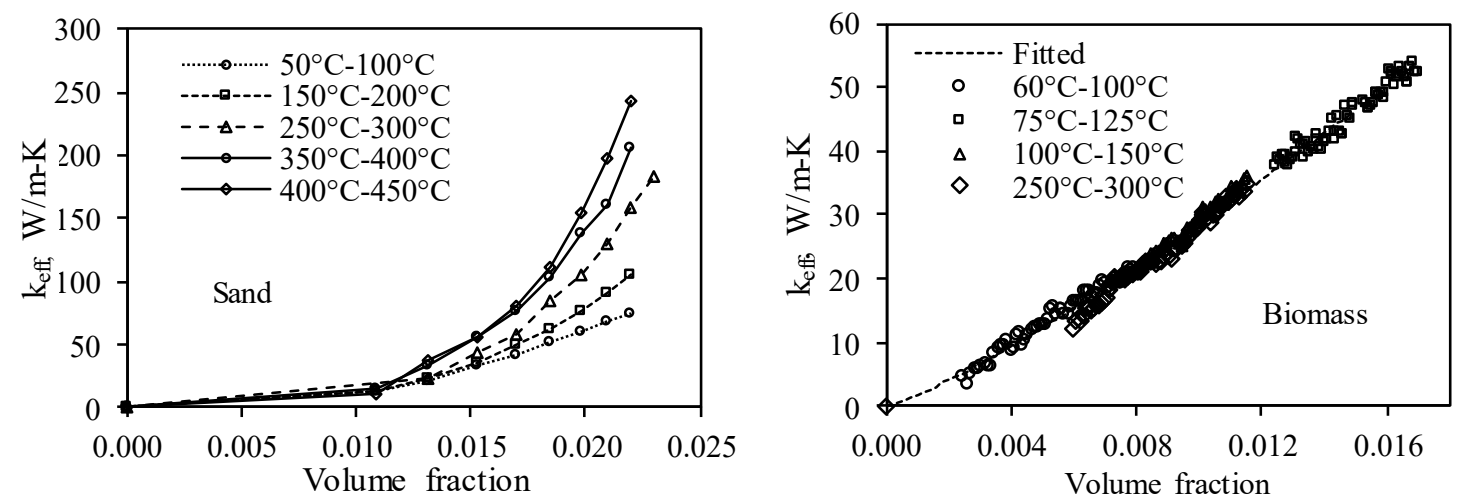

Figure 3.5: Effective thermal conductivity of sand, $\mathrm{k}_{\mathrm{eff}}$, vs. solid volume fraction in reactor at the temperature range $50^{\circ} \mathrm{C}$ $450^{\circ} \mathrm{C}$.

Figure 3.6: Effective thermal conductivity of biomass, $\mathrm{k}_{\text {eff }} \mathrm{vs}$. solid volume fraction in reactor at the temperature range $60^{\circ} \mathrm{C}$ $300^{\circ} \mathrm{C}$.

For biomass it is seen from Figure 3.6, that the effective thermal conductivity is approximately independent of temperature at applicable volume fractions, and increases with solid volume fraction. Only a small dependence on temperature is observed for sand 
within this volume fraction range as well. The effective thermal conductivity for biomass can be given by

$$
k_{e f f}=7,414 \emptyset^{1.21} T^{0}
$$

Biomass exhibits less dependence on the solid filling fraction compared to sand as indicated by the power of $\emptyset$ in eq. 21 and eq. 22 Interestingly, the effective thermal conductivities of the two materials are of similar magnitude at temperatures below $300^{\circ} \mathrm{C}$ and volume fractions below 0.016. This indicates the analysis is consistent, and that effective coefficient may be a good proxy for the heat transfer within the reactor. It is to be noted that the effective thermal conductivity is not truly a conductivity but rather a measurement of heat transfer coefficient. As effective thermal conductivity is experimentally obtained it accounts for all the mechanisms of heat transfer including convection which is primarily expected to be the main heat transfer mechanism in the reactor. Thus temperature effects shown in Figure 3.5 \& Figure 3.6 are not to be compared with the thermal conductivity values of the materials. The name effective thermal conductivity was used based on the approach we used to measure heat transfer in the reactor.

\subsection{Heating rate}

The steady state temperature gradient without HTM is measured from experiments as explained in section 2.6. In the presence of HTM, a simple model which can calculate the heating time is described in this section. 


\subsubsection{With HTM}

When carrying out fast pyrolysis in the presence of HTM, the sand to biomass mass ratio of 15 is used as described in the previous work (Zinchik et al., 2017). This corresponds to running M2 (refer Figure 2.1) at $6 \mathrm{rpm}$ for sand and M1 (refer Figure 2.1) at $4 \mathrm{rpm}$ for biomass. The model explained in section 2.7 is used to obtain the transient temperature behavior.

Table 3.1 shows the values used for the parameters of model. The sand and biomass phase density is assumed to be invariant with temperature. The solid volume fraction and volume was calculated using eq. 5 and eq. 6 for sand and biomass respectively. The specific heat capacity expressions for $c_{p s}$ (sand) and $c_{p b}$ (biomass) (eq. $19 \&$ eq. 20) were substituted in eq.16 and eq.17. On mixing both streams, the mixture volume fraction would be the sum of the volume fraction of sand and biomass respectively. Thus, the effective thermal conductivity for the mixture will be higher due to the higher filling fraction. Note that comparing Figure 3.5 and Figure 3.6 it is seen that for the same range of volume fraction

we observe similar values of $k_{e f f}$ for sand and biomass. This indicates $k_{e f f}$ to be more reactor dependent than material dependent. It is thus assumed the mixture effective thermal conductivity $K_{\text {eff }}$ (refer eq. 18) to be equal to that of sand. Thus $K_{\text {eff }}$ is calculated from eq. 21 with solid volume fraction of 0.026 . 
Table 3.1: Properties/parameters for one dimensional model

\begin{tabular}{|l|l|}
\hline Sand phase bulk density (measured) & $1800 \mathrm{~kg} / \mathrm{m}^{3}$ \\
\hline Biomass (sawdust) phase bulk density & $288 \mathrm{~kg} / \mathrm{m}^{3}$ \\
\hline Sand volume fraction & 0.01978 \\
\hline Biomass (sawdust) volume fraction & 0.00632 \\
\hline Mixture volume fraction & 0.0261 \\
\hline Characteristic length & $0.0125 \mathrm{~m}$ \\
\hline Cross section area & $0.0005 \mathrm{~m}^{2}$ \\
\hline Volume of sand phase & $4.2 \mathrm{e}-6 \mathrm{~m}^{3}$ \\
\hline Volume of biomass phase & $1.35 \mathrm{e}-6 \mathrm{~m}^{3}$ \\
\hline
\end{tabular}

Due to the nonlinear nature of eq. 16 and eq. 17, they were solved using the RK-4th order method. The time step used in this method was 1e-4 s. Figure 3.7 and Figure 3.8 shows the temperature and heating rate transient curve. It is seen that the instantaneous heating rate of up to $530 \mathrm{~K} / \mathrm{s}$ is observed. The steady state temperature obtained is about $753 \mathrm{~K}$ assuming no losses. Note that the mass of sand is 15 times that of biomass, hence there is little change in the sand phase's temperature. 


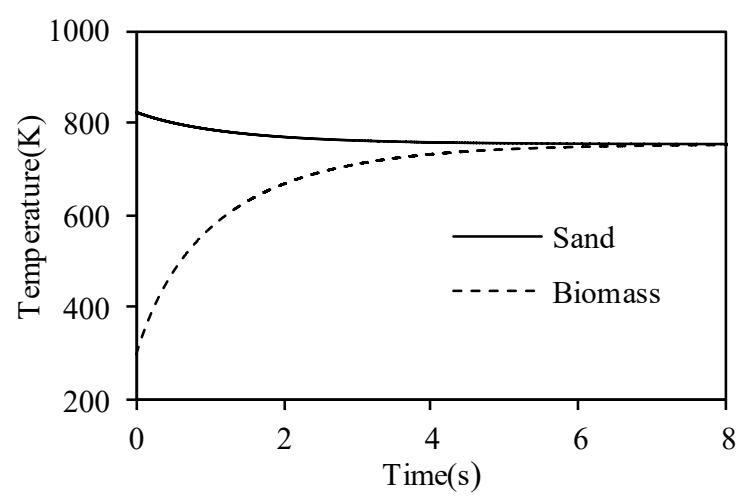

Figure 3.7: Temperature transient of fast pyrolysis of biomass (sawdust) with sand as HTM

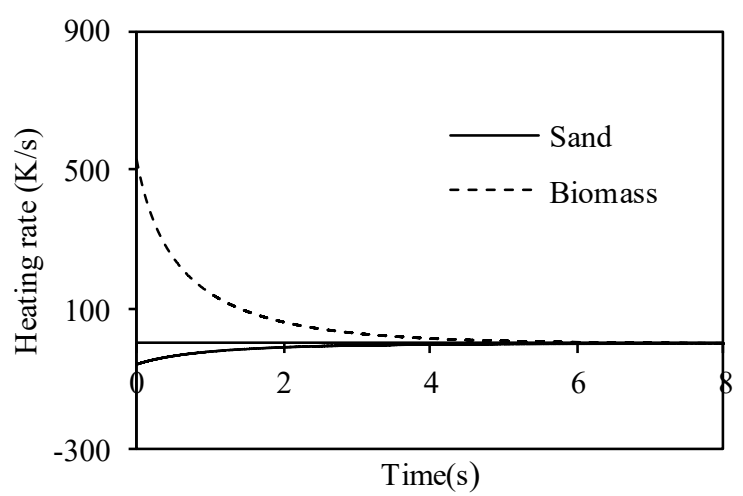

Figure 3.8: Heating rate transient for fast pyrolysis of biomass (sawdust) with sand as HTM

\subsubsection{Without HTM}

Figure 3.9 below shows the measured heating rate for biomass (sawdust) vs. solid volume fraction without $\mathrm{HTM}$ with set temperatures of $75^{\circ} \mathrm{C}$ for heaters $1-5$ and $125^{\circ} \mathrm{C}$ for heaters 6-10. The thermocouples measure temperatures on reaching steady state. The spatial temperature gradient is then calculated by

$$
\frac{d T}{d x} \approx \frac{T_{5}-T_{4}}{0.0254}
$$




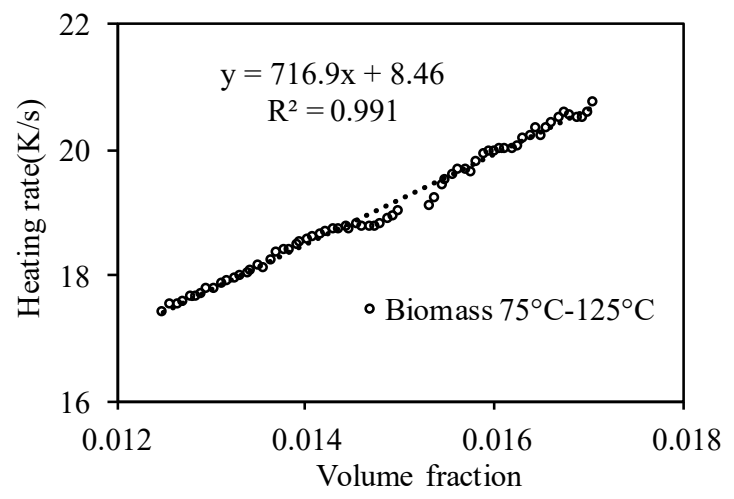

Figure 3.9: Heating rate vs solid volume fraction of biomass in the temperature range $75^{\circ} \mathrm{C}-125^{\circ} \mathrm{C}$.

Where $T_{5}$ and $T_{4}$ are the temperature readings from thermocouples 5 and $4.0 .0254 \mathrm{~m}$ is the distance between the thermocouples 5 and 4 . The temperature gradient was converted to heating rate by using eq. 13. Figure 3.9 indicates that the heating rate is a linear function of the solid volume fraction. It is important to note that we have a heating rate value greater than $15 \mathrm{~K} / \mathrm{s}$, the threshold value after which heating rate does not affect liquid yield rate (Di Blasi, 1996). As will be explained in the next section when fast pyrolysis experiment was conducted for torrefied pine forest residues with temperature gradient (refer Figure 3.10) settings of $350^{\circ} \mathrm{C}$ (heaters $1-5$ ) and $500^{\circ} \mathrm{C}$ (heaters 6-10), a steady state heating rate of $36 \mathrm{~K} / \mathrm{s}$ was obtained. This implies that at higher temperatures, there is an increase in heating rates. This is a good indication that fast pyrolysis can be performed without the presence of HTM for this reactor 


\subsection{Effect on liquid yield}

As mentioned in the previous section, sufficient heating rates for fast pyrolysis without the presence of HTM were obtained. Biomass is often pretreated before undergoing pyrolysis. Torrefaction is one such pretreatment process used. Torrefaction removes moisture as well as densifies the material. Batidzirai et al discusses more about the advantages of torrefying biomass (Batidzirai, Mignot, Schakel, Junginger, \& Faaij, 2013). To study the effect of heating rates on torrefied biomass (pine forest residues) the model developed by Klinger et al. was used (Klinger, Bar-Ziv, \& Shonnard, 2015). The heating rate profile for the model was measured from the experiment. The experiment was performed by flowing torrefied pine forest residues into the reactor with heaters $1-5$ at $350^{\circ} \mathrm{C}$ and heaters $6-10$ at $500^{\circ} \mathrm{C}$.

Figure 3.11 shows the liquid yield for different heating rates (including the experimental heating rate of $36 \mathrm{~K} / \mathrm{s}$ ) obtained from the model. It is observed that the liquid yield obtained is approximately $66 \sim 67 \%$ (when the yield from torrefaction is combined with pyrolysis) for the ideal, mineral free biomass. The experimental (demineralized) yield obtained was $53 \%$. If the $9-12 \%$ liquid from torrefaction is combined with the pyrolysis yields obtained,

there is reasonable agreement to the ideal model predictions. Note that a heating rate of $12 \mathrm{~K} / \mathrm{s}$ is sufficient to ensure that the liquid product yield is not affected 


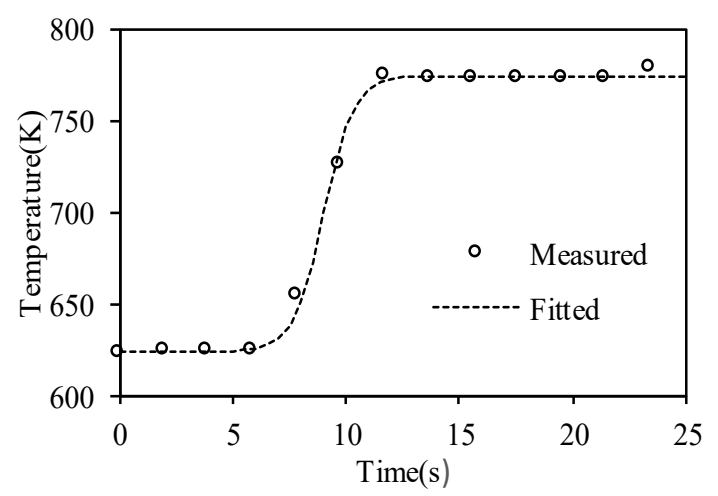

Figure 3.10: Experimental temperature profile for fast pyrolysis of torrefied pine forest residues without HTM

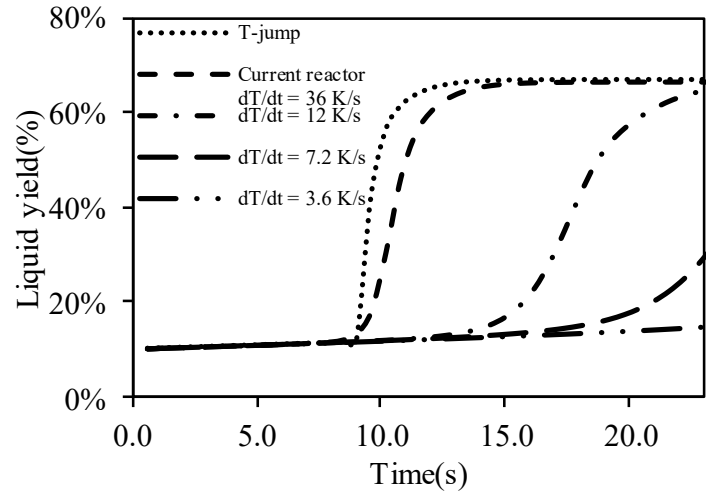

Figure 3.11: Liquid yield as predicted by the Klinger et al. model for various heating rates

within this system. This is another indication that there is sufficient heating rates to ensure fast pyrolysis.

Table 3.2 below summarizes the pyrolysis experimental results obtained

Table 3.2: Experimental results

\begin{tabular}{|l|l|}
\hline Feedstock & Liquid yield (\%) \\
\hline Raw forest residues with HTM & 55 \\
\hline Torrefied pine forest residues with HTM & $44 \sim 46,53$ (demineralized) \\
\hline $\begin{array}{l}\text { Torrefied pine forest residues without } \\
\text { HTM }\end{array}$ & 50 \\
\hline
\end{tabular}

From Table 3.2 and Figure 3.11 it is seen that the experimental yield is 53\% in comparison to the $54 \%$ as predicted by the model. In addition to the experimental errors, the condenser and scrubber may not condense all condensable gas vapors. This means that some of the 
condensable gas vapors may be lost along with the non-condensable gases. The feedstock composition may vary compared to the one used in the model. Some amount of secondary reactions may take place in the heat transfer line.

\section{Conclusions and future work}

Accurate correlations for specific heat capacity were developed for sand and biomass. Correlations for heat transfer coefficients showed that heat transfer increased significantly at higher filling fractions for sand and biomass. Temperature dependence on heat transfer coefficient was only shown by sand for the applicable volume fractions. The similar values for effective thermal conductivity for biomass and sand at same fill fractions indicate that effective coefficient may be a good proxy for the heat transfer within the reactor. In future reactor designs there is scope for increasing solid fill fraction as better heat transfer characteristics has been observed at higher fill fractions. From the one-dimensional heat transfer model, heating time of $3 \mathrm{~s}$ and instantaneous heating rate of $530 \mathrm{~K} / \mathrm{s}$ were observed. The threshold-heating rate of $12 \mathrm{~K} / \mathrm{s}$ was obtained for fast pyrolysis of torrefied pine forest residues. The experimentally measured heating rate is higher than this threshold value at $36 \mathrm{~K} / \mathrm{s}$. This ensures that our paddle auger reactor complies with the fast pyrolysis requirements in the presence and absence of HTM. This is significant, as one of the drawbacks of using sand as an HTM is its abrasive nature, which can damage reactor/system components. The result of this work is very important for scaling up the process. The next step would be to scale up the system from 1-inch to a 4-inch reactor. This would scale the mass flow by 16 times. In order to ensure higher filling fractions in the 
reactor, an effective biomass feeding system must be developed. As the diameter of the reactor increases the biomass conductivity and reaction kinetics are expected to play a greater role in addition to the mixing provided by the reactor. In the future, the group is also examining the possibility of having an integrated torrefier and pyrolysis unit. 


\section{References}

Abdelmotalib, H. M., Youssef, M. A. M., Hassan, A. A., Youn, S. B., \& Im, I.-T. (2015). Heat transfer process in gas-solid fluidized bed combustors: A review. International Journal of Heat and Mass Transfer, 89, 567-575. doi:http://dx.doi.org/10.1016/j.ijheatmasstransfer.2015.05.085

Aramideh, S. (2014). Numerical simulation of biomass fast pyrolysis in fluidized bed and auger reactors. (Masters), Iowa state university. (14093)

Batidzirai, B., Mignot, A. P. R., Schakel, W. B., Junginger, H. M., \& Faaij, A. P. C. (2013). Biomass torrefaction technology: Techno-economic status and future prospects. Energy, 62, 196-214. doi:http://dx.doi.org/10.1016/j.energy.2013.09.035

Boateng, A. A., Daugaard, D. E., Goldberg, N. M., \& Hicks, K. B. (2007). Bench-Scale Fluidized-Bed Pyrolysis of Switchgrass for Bio-Oil Production. Industrial \& Engineering Chemistry Research, 46(7), 1891-1897. doi:10.1021/ie0614529

Bridgwater, A. V. (2012). Review of fast pyrolysis of biomass and product upgrading. Biomass and Bioenergy, 38, 68-94. doi:http://dx.doi.org/10.1016/j.biombioe.2011.01.048

Bridgwater, A. V., Meier, D., \& Radlein, D. (1999). An overview of fast pyrolysis of biomass. Organic Geochemistry, 30(12), 1479-1493. doi:http://dx.doi.org/10.1016/S0146-6380(99)00120-5 
Bridgwater, A. V., \& Peacocke, G. V. C. (2000). Fast pyrolysis processes for biomass. Renewable and Sustainable Energy Reviews, 4(1), 1-73.

doi:http://dx.doi.org/10.1016/S1364-0321(99)00007-6

Briens, C., Piskorz, J., \& Berruti, F. (2008). Biomass Valorization for Fuel and Chemicals Production -- A Review International Journal of Chemical Reactor Engineering (Vol. 6).

Brown, J. N. (2009). Development of a lab-scale auger reactor for biomass fast pyrolysis and process optimization using response surface methodology. (Masters), Iowa state university. (10996)

Chun, Y. N., Kim, S. C., \& Yoshikawa, K. (2011). Pyrolysis gasification of dried sewage sludge in a combined screw and rotary kiln gasifier. Applied Energy, 88(4), 11051112. doi:http://dx.doi.org/10.1016/j.apenergy.2010.10.038

Damartzis, T., \& Zabaniotou, A. (2011). Thermochemical conversion of biomass to second generation biofuels through integrated process design-A review. Renewable and Sustainable Energy Reviews, 15(1), 366-378. doi:http://dx.doi.org/10.1016/j.rser.2010.08.003

Day, M., Cooney, J. D., \& Shen, Z. (1996). Pyrolysis of automobile shredder residue: an analysis of the products of a commercial screw kiln process. Journal of Analytical and Applied Pyrolysis, 37(1), 49-67. doi:http://dx.doi.org/10.1016/0165-

\section{$\underline{2370(96) 00938-2}$}

Debdoubi, A., El amarti, A., Colacio, E., Blesa, M. J., \& Hajjaj, L. H. (2006). The effect of heating rate on yields and compositions of oil products from esparto pyrolysis. 
International Journal of Energy Research, 30(15), 1243-1250. doi:10.1002/er.1215

Di Blasi, C. (1996). Kinetic and Heat Transfer Control in the Slow and Flash Pyrolysis of Solids. Industrial \& Engineering Chemistry Research, 35(1), 37-46. doi:10.1021/ie950243d

Dupont, C., Chiriac, R., Gauthier, G., \& Toche, F. (2014). Heat capacity measurements of various biomass types and pyrolysis residues. Fuel, 115, 644-651. doi:http://dx.doi.org/10.1016/j.fuel.2013.07.086

Hafez, O., \& Bhattacharya, K. (2012). Optimal planning and design of a renewable energy based supply system for microgrids. Renewable Energy, 45, 7-15. doi:http://dx.doi.org/10.1016/j.renene.2012.01.087

Haynes, W. M. (2012). CRC handbook of chemistry and physics: CRC Press.

Henrich, E., Dahmen, N., Weirich, F., Reimert, R., \& Kornmayer, C. (2016). Fast pyrolysis sof lignocellulosics in a twin screw mixer reactor. Fuel Processing Technology, 143, 151-161. doi:http://dx.doi.org/10.1016/j.fuproc.2015.11.003

IEABioenergyTask34. (2016). Reactors - Bubbling fluid beds. Retrieved from

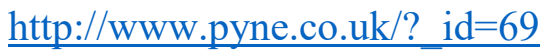

Klinger, J., Bar-Ziv, E., \& Shonnard, D. (2015). Unified kinetic model for torrefactionpyrolysis. Fuel Processing Technology, 138, 175-183.

doi:http://dx.doi.org/10.1016/j.fuproc.2015.05.010 
Luo, G., Chandler, D. S., Anjos, L. C. A., Eng, R. J., Jia, P., \& Resende, F. L. P. (2017). Pyrolysis of whole wood chips and rods in a novel ablative reactor. Fuel, 194, 229-238. doi:http://dx.doi.org/10.1016/j.fuel.2017.01.010

McMaster-Carr. Thermocouple probes with armored cable for solids. Retrieved from https://www.mcmaster.com/\#type-k-thermocouples/=16m0c88

Mohan, D., Pittman, C. U., \& Steele, P. H. (2006). Pyrolysis of Wood/Biomass for Biooil: A Critical Review. Energy \& Fuels, 20(3), 848-889. doi:10.1021/ef0502397

Muradov, N. Z., \& Veziroğlu, T. N. (2008). Green path from fossil-based to hydrogen economy: an overview of carbon-neutral technologies. International journal of hydrogen energy, 33, 6804-6839.

Nations, U. (1998). Kyoto protocol to the united nations framework convention on climate change.

Nations, U. (2015). Paris agreement.

NIST. Quartz (SiO2). Retrieved from http://webbook.nist.gov/cgi/cbook.cgi?ID=C14808607\&Type=JANAFS\&Table= on\#Notes

Onay, O. (2007). Influence of pyrolysis temperature and heating rate on the production of bio-oil and char from safflower seed by pyrolysis, using a well-swept fixed-bed reactor. Fuel Processing Technology, 88(5), 523-531. doi:http://dx.doi.org/10.1016/j.fuproc.2007.01.001

Puy, N., Murillo, R., Navarro, M. V., López, J. M., Rieradevall, J., Fowler, G., . . Mastral, A. M. (2011). Valorisation of forestry waste by pyrolysis in an auger 
reactor. Waste Management, 31(6), 1339-1349.

doi:http://dx.doi.org/10.1016/j.wasman.2011.01.020

Rabier, F., Temmerman, M., Böhm, T., Hartmann, H., Daugbjerg Jensen, P., Rathbauer, J., ... Fernández, M. (2006). Particle density determination of pellets and briquettes. Biomass and Bioenergy, 30(11), 954-963. doi:http://dx.doi.org/10.1016/j.biombioe.2006.06.006

Roegiers, J., Pieters, J. p., \& Ronsse, F. p. (2016). Heat and mass transfer modelling of auger reactors: 2016.

Shaw, M. (2006). Pyrolysis of lignocellulosic biomass to maximize bio-oil yield: an overview. Paper presented at the CSBE/SCGAB 2006 Annual conference, Edmonton, Alberta, Canada.

Trendewicz, A., Braun, R., Dutta, A., \& Ziegler, J. (2014). One dimensional steady-state circulating fluidized-bed reactor model for biomass fast pyrolysis. Fuel, 133, 253262. doi:http://dx.doi.org/10.1016/j.fuel.2014.05.009

Verma, M., Godbout, S., Brar, S. K., Solomatnikova, O., Lemay, S. P., \& Larouche, J. P. (2011). Biofuels production from biomass by thermochemical conversion technologies. International Journal of Chemical Engineering, 2012, 18. doi:http://dx.doi.org/10.1155/2012/542426

Veses, A., Aznar, M., Martínez, I., Martínez, J. D., López, J. M., Navarro, M. V., . . . García, T. (2014). Catalytic pyrolysis of wood biomass in an auger reactor using calcium-based catalysts. Bioresource Technology, 162, 250-258. doi:http://dx.doi.org/10.1016/j.biortech.2014.03.146 
Wagenaar, B. M., Kuipers, J. A. M., Prins, W., \& van Swaaij, W. P. M. (1993). The Rotating Cone Flash Pyrolysis Reactor. In A. V. Bridgwater (Ed.), Advances in Thermochemical Biomass Conversion (pp. 1122-1133). Dordrecht: Springer Netherlands.

Zinchik, S., Klinger, J., Westover, T., Donepudi, Y., Naber, J., \& Bar-Ziv, E. (2017). Evaluation of fast pyrolysis feedstock conversion with a mixing paddle reactor. Manuscript submitted for publication. 